\title{
Quantifying Depth of Burial and Composition of Shallow Buried Archaeological Material: Integrated Sub-bottom Profiling and 3D Survey Approaches
}

\author{
Trevor Winton
}

\begin{abstract}
This chapter presents proof of concept results from a program of in situ experimental and shipwreck survey measurements using non-linear (parametric) sub-bottom profiler (SBP) acoustic technology. Currently adopted acoustic methods have practical limitations for in situ management purposes for underwater sites with buried archaeological material. Sidescan and multibeam sensors do not quantify material buried below the seabed; linear SBP surveys are challenging to operate in very shallow water and have difficulties with respect to interpretation in the top $30 \mathrm{~cm}$ of the seabed; and confidence estimates for parametric SBP depth of burial measurements have yet to be published. The prime purposes of this research, consequently, are: to quantify shallow buried archaeological sites in 3D with confidence estimates, by measuring the depth of sediment cover, thickness and lateral extent of buried archaeological material; and to investigate relationships between acoustic waveform parameters and the type and degradation condition of that buried material. This improved measurement and interpretation capability, when combined with the other geophysical search tools such as multibeam echo sounders and magnetometers, will also aid in the assessment of the archaeological research potential of underwater sites.
\end{abstract}

\section{Keywords}

Marine geophysics · In situ management · Parametric sonar $\cdot$ Underwater cultural heritage
T. Winton $(\square)$

Maritime Archaeology Program, Flinders University,

Adelaide, SA, Australia

e-mail:wint0062@flinders.edu.au

\subsection{Introduction}

The trend in maritime archaeology to favour in situ preservation over more destructive methods, has led to an increased need to measure burial depths and composition of shallowburied material using non-invasive methods. This has been discussed widely within the archaeological community (Bergstrand and Godfrey 2007; Gregory 2007; Richards 2011a; Richards et al. 2014; Shefi and Veth 2015) and continues to evolve pragmatically as technological improvements result in the increased discovery of UCH. Simultaneously, excavation, conservation, storage, and display costs continue to increase. Furthermore, there is usually a significant time gap between discovery and potential site excavation, thus many sites awaiting investigation may require protection in the interim period in order to maintain the quality of the archaeological material (Manders et al. 2008). The protection of UCH through in situ preservation as a first option has also been consistently emphasized for preserving submerged and waterlogged cultural heritage for future generations, and politically galvanized by UNESCO in Article 2 of the 2001 Convention on the Protection of the Underwater Cultural Heritage (UNESCO 2001).

The ultimate in situ preservation goal for many heritage managers is the ability to maintain or create a stable, protective environment (Manders et al. 2008; Ortmann et al. 2010) to conserve as much as possible of the currently remaining archaeological material. Decisions on how to achieve this goal need to be based on the understanding of the true site extent, the types of material present and their state of degradation, and the potential exposure of archaeological material on a site (both which is visible on or above the seabed, and which may lie beneath the seabed - and in many situations, is neither visible nor known) (Gregory and Matthiesen 2012; Richards et al. 2014; Wheeler 2002; Winton 2015).

Burial depth, and the continuity of this sediment coverage through time, is the single most important site-specific influence on the rate of degradation of shipwreck material 
(Stewart 1999; Winton 2015). Studies have shown that the extent of biological degradation of organic materials decreases considerably with burial depths greater than $50 \mathrm{~cm}$, where anaerobic conditions limits the effects of marine borers, fungi and most bacteria, and would be suitable for the preservation of timbers (Björdal et al. 2000; Gregory 1998; Richards 2011b; Shefi and Veth 2015). If electrically isolated metal components are buried in anaerobic sediments, then aerobic corrosion mechanisms are also avoided. By contrast, materials with shallower depths of sediment coverage are subject to much higher aerobic microbiological and chemical degradation rates and can also be exposed to combined physical and biological degradation processes if the shallow protective sediment layer is eroded, or purposefully excavated.

Effective in situ management of maritime archaeological sites consequently requires a priori $3 \mathrm{D}$ information to identify: if archaeological material is buried below the seabed (or riverbed or lakebed); its lateral extent and depth of burial, especially if this depth is less than $50 \mathrm{~cm}$; the major material types both exposed and potentially buried; and their state of deterioration. Currently this information is gained from the outcomes of long-term or episodic seabed erosion, or purposeful excavation. As both expose previously buried anaerobic material to aerobic conditions, however, a proven non-invasive method to measure and identify shallow-buried material is desired.

\subsection{Non-invasive Geophysical Measurements}

A variety of marine seismic reflection techniques, including single beam and Multibeam echo sounders (SBES, MBES), sidescan sonar (SSS), synthetic aperture sonar (SAS) and subbottom profilers (SBP) have been progressively used since the early 1950s to investigate a range of submerged geomorphological and archaeological sites (Bjørnø 2017b, c; Dix et al. 2008; Quinn 2012). SBES, MBES, SSS and SAS devices have traditionally been used for bathymetric mapping and visualizing the seabed and objects on, or above, the seabed. Single beam acoustic ground discrimination systems (AGDS) are based on SBES and used to classify seabed type and map submerged archaeological materials lying on the seabed (Lawrence and Bates 2001). Sub-bottom imaging is carried out with highfrequency seismic profiling systems. Significant advances in the development of SBP technology, including analysis and imaging software (Bull et al. 2005; Missiaen et al. 2005; Müller et al. 2005; Plets et al. 2009; Wunderlich and Müller 2003) led in situ managers (Manders et al. 2008) to the view that 'SBP instruments provide a non-intrusive view of material below the seabed and that sites could then be managed with material still in their protective burial environment.'
Nearly all the published SBP surveys of underwater shipwreck sites have used Chirp SBPs which were first developed in 1981. From 2001 this system was optimized and enhanced as 2D systems, and subsequently 3D, at the University of Southampton. Descriptions of these applications is given by Arnott et al. (2005), Cvikel et al. (2017), Dix et al. (2008), Forrest et al. (2005); Grøn and Boldreel (2013), Grøn et al. (2015), Lafferty et al. (2006), Plets et al. (2005, 2008, 2009), Quinn et al. (1997a, b, c, 1998a, b), and Vardy et al. (2008). The earlier SBP surveys were effectively used to help locate or map site extent, and qualitatively improve understanding of site formation processes on the Invincible, Mary Rose, La Surveillante and Pandora shipwreck sites (Forrest et al. 2005; Quinn et al. 1997a, b, c, 1998a, b, 2002). Following improvements in data processing and data interpretation processes, quantitative analysis of shipwreck sites became possible whereby derived reflection coefficients were used to predict the degradation state of the buried ship's timbers (Arnott et al. 2005; Bull et al. 1998; Quinn et al. 1997b) as well as the 3D shape of the buried ship remains (Plets et al. 2008, 2009).

Despite these successful applications, there are difficulties for heritage managers to use (linear) Chirp SBP systems for in situ management purposes, especially in shallow ( $<5 \mathrm{~m}$ water depths) owing to vessel-induced bubble turbulence, restricted acoustic geometry of the system, wide acoustic beam patterns and inability to discriminate in the top $30 \mathrm{~cm}$. While Chirp systems can be pulled by divers to avoid boat noise interference (Plets et al. 2007, 2009) and data processing techniques can be used to correct for geometry and optimize the processing of the collected data, their field operability remains difficult (Bjørnø 2017c). Chirp SBPs use wide acoustic beam patterns $\left(20-30^{\circ}\right)$ which limits horizontal resolution. Although instrument technical improvements have progressively improved resolution in shallow water depths from approximately 2-3 m (Plets et al. 2008 ) to $0.4-0.7 \mathrm{~m}$ resolution (Plets et al. 2009) and 'decimeter resolution' (Gutowski et al. 2015), finer resolution to $0.25 \mathrm{~cm}$ (horizontal) and around $4.5 \mathrm{~cm}$ (vertical) can only be achieved in $3 \mathrm{D}$ by expert use of post-processing software (Dix, personal communication, 22 December 2017). Bull et al. (1998) report that small lateral variations in the verynear surface sediments have a profound effect on Chirp acoustic returns in the top $30 \mathrm{~cm}$ of the seabed, resulting in high uncertainty in very shallow sub-bottom measurement, unfortunately at precisely in the depth range of maximum importance.

SBPs based on nonlinear acoustic phenomena have advanced from early experimental acoustic arrays developed in the mid-1980s, and due to their inherently different acoustic wave characteristics, have stronger in situ management potential for sub-bottom profiling of shallow buried archaeological material. Nonlinear (parametric) SBPs 
produce low-frequency pulses (secondary difference-frequencies) as an outcome of the interaction between two simultaneously generated high sound pressure, higher-frequency (primary) sound waves transmitted at slightly different frequencies. Advantageous (seabed penetrating) pulse qualities includes narrow $\left( \pm 2^{\circ}\right)$ beam width with consequential high horizontal resolution; very low side-lobe levels, which reduce clutter and signal-to-noise ratios and enhance the separation of backscattering from seafloor and sub-surface reflectors, leading to improved ability to detect very shallow and acoustically weak reflectors. They also include high pulse repetition rates allowing more 'hits' per target and higher boat survey speeds and a smaller combined transmitter/receiver array which significantly improves field operability as it can be vertically mounted from a vessel, rather than towed in an array (Bjørnø 2017a, c; Caiti et al. 1999; Wunderlich et al. 2005a, b).

Commercially available parametric SBPS include Atlas Hydrographic GmbH (Parasound), Germany; Kongsberg Defence Systems (TOPAS PS systems), Norway; and Innomar Technologie GmbH, Germany (SES-2000) (Bjørnø 2017a). Both the TOPAS PS and SES-2000 systems are available in different models optimized to operate in different water depths from very shallow water to full ocean depth, and while the TOPAS is best known in the parametric SBP range, it is less popular due to its high cost (Kozaczka et al. 2013).

Missiaen et al. (2008) used a parametric SBP in a comparative assessment of different shallow geophysical methods and, as this technique demonstrated the highest measurement resolution, it was then subsequently used to record complex geomorphological structures in a shallow tidal estuary. Parametric SBPs have also been used to detect surface and shallow buried steel pipelines, cables, spheres and steel canisters (Kozaczka et al. 2013; Vasudevan et al. 2006; von Deimling et al. 2016). Their application to maritime archaeological sites has also been demonstrated through an experimental deployment of an SBP on a ROV in deep water in the eastern Mediterranean to map two Phoenician ships (Mindell and Bingham 2001) as well as a trial to identify a narrow $0.2 \mathrm{~m}$ diameter wooden post and other embedded wooden archaeological objects in the Baltic (Müller and Wunderlich 2003; Wunderlich et al. 2005b). Other examples include case studies of the identification of possible remains of Roman dykes and human activities including salt/peat exploitation in prehistoric tidal gullies (Ostend, Belgium) and of an exposed shipwreck on the Buiten Ratel sandbank (Belgium) (Missiaen 2010); and seismic imaging of the scattered remains of the Dutch East Indiaman ' $t$ Vliegent Hart (Missiaen et al. 2012). More recently Innomar Technologie $\mathrm{GmbH}$ introduced a multi-transducer sub-bottom profiler to capture very high data density in shallow waters (SES-2000 quattro) which can be subsequently viewed in 3D using grid- ding and visualization software. Missiaen et al. (2017) conducted 3D seismic surveys using the SES-2000 quattro across shallow intertidal areas at the coastal site of OstendRaversijde, Belgium. This complemented the previous 2D parametric surveys on this site and provided an image of the complex peat exploitation patterns, the features of which matched with old aerial photographs.

With the exception of the Kozaczka et al. (2013) buried canister trial and the post-measurement dredging and recovery of measured cylinders and poles (Gutowski et al. 2015; Vardy et al. 2008), there has been no reported quantitative verification of linear or non-linear SBP performance (e.g., accuracy of depth of cover estimates, Type I and Type II errors associated with the correct identification/interpretation of a buried reflector, assessment of different reflector material types) through testing against previously surveyed and reburied shipwreck materials. Hence, there is clearly a need for such a trial to assess SBP performance, and particularly for the reported more favorable performance characteristics of the parametric SBP, in mapping shallow buried archaeological material. The following sections describe a research plan and field survey (proof of concept) results to assess the performance and data interpretation capabilities of a parametric SBP for in situ management purposes, and using complimentary tools, to identify and characterize shallow buried archaeological material.

\subsection{Parametric SBP Surveys}

This research quantifies the accuracy and variability associated with the non-invasive parametric SBP measurements of shallow depths of sediment burial, as well as investigating the potential relationships between acoustic wave parameters and types and condition of a variety of buried material. This was achieved through both in situ experimental burial and comparative in situ wreck-site surveys.

\subsubsection{In Situ Experimental Burial Survey}

The in situ experimental component involved shallow burial of timber beams ('sleepers') at different burial depths (10, 30 and $50 \mathrm{~cm}$ ) with different grain orientations and in different sediment types. Following a period of reconsolidation of the sediments (after underwater excavation and back-filling the holes around and over the buried timbers), these sleepers were measured with an Innomar parametric SES-2000 compact SBP. The experimental parameters, listed in Table 10.1, were chosen to be representative of equipment measurement capabilities and in situ conditions on a range of wreck sites. Mid-coarse-grained sands and fine silts-muds represent the typical endpoints in both the range of sediment environments 
Table 10.1 In situ experimental parameters

\begin{tabular}{|c|c|}
\hline Parameter & $\begin{array}{l}\text { Included within in situ experimental } \\
\text { burial survey }\end{array}$ \\
\hline \multirow[t]{2}{*}{ Sediment environment } & Mid-coarse grained sands and \\
\hline & Fine grained silty sands ${ }^{\mathrm{a}}$ \\
\hline \multirow[t]{3}{*}{ Timber types } & European Oak (Quercus robur) \\
\hline & Pine (Pinus radiata) \\
\hline & 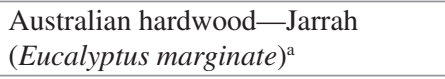 \\
\hline \multirow{2}{*}{$\begin{array}{l}\text { Timber sample size } \\
\text { (nominal) }\end{array}$} & $50 \times 12.5 \times 12.5 \mathrm{~cm}$ (sleepers) \\
\hline & $12.5 \times 12.5 \times 12.5 \mathrm{~cm}$ (blocks) $^{\mathrm{b}}$ \\
\hline $\begin{array}{l}\text { Burial depths/depths of } \\
\text { sediment cover }\end{array}$ & $10 \mathrm{~cm}, 30 \mathrm{~cm}, 50 \mathrm{~cm}$ \\
\hline Replication & Triplicates \\
\hline Grain orientation & $\begin{array}{l}\text { Longitudinal grain horizontal and } \\
\text { vertical }\end{array}$ \\
\hline Timber stacking & Single, $10+30 \mathrm{~cm}, 10+30+50 \mathrm{~cm}$ \\
\hline
\end{tabular}

a Not yet installed

${ }^{b}$ For ease of removal, blocks with depths of burial of $30 \mathrm{~cm}$ and $50 \mathrm{~cm}$ were cut with a $45^{\circ}$ taper on top. Blocks with $10 \mathrm{~cm}$ depth of burial remained with flat top, otherwise taper would protrude above seabed surface

in which maritime archaeological material lies buried, and the sediment penetration range for the SBP. To date, sleepers have been buried adjacent to the James Matthews (1841) wreck site on the northern side of Woodman Point, approximately $7 \mathrm{~km}$ south of Fremantle, Western Australia (Fig. 10.1). Here water depths range $1.5-2.8 \mathrm{~m}$ and the calcareous sediments have been characterized as medium sands with some coarse-grained skeletal material (Richards et al. 2009). European oak and pine represent timbers commonly used in European shipbuilding (Zisi 2016), and Australian hardwood was commonly used in Australian colonial-period shipbuilding (O'Reilly 2007; Pemberton 1979; Staniforth and Shefi 2014). The cross-sectional dimensions of the timber samples were based on the theoretical measurement resolution of the SBP $(<5 \mathrm{~cm}$ vertical and $5-10 \mathrm{~cm}$ horizontal, respectively, in water depths $1.5-2.8 \mathrm{~m}$ and burial depths 0.1-0.5 m (Bergersen 2016 pers. comm. 29 July). Timber grain orientation reflects the different acoustic properties of timber (Arnott et al. 2005) and timber orientations likely to be found on shipwreck sites (Zisi 2016).

The replicated experimental design permits statistical analysis of the accuracy and variability associated with SBP measurements of timber sleepers buried at three shallow depths $(10 \mathrm{~cm}, 30 \mathrm{~cm}$ and $50 \mathrm{~cm}$ ), the ability to characterize any acoustic 'signatures' from different timber species (currently pine and oak) and to assess whether-or-not timber grain orientation is a significant variable in in situ acoustic measurements. Stacking of the timbers replicates what might be found on some wreck sites and may reveal the ability and acoustic strength of the SBP system to measure multiple layers of timbers. It is intended to leave the buried sleepers in place for at least 5 years, enabling repeated SBP measurements on an annual basis to determine if the acoustic 'signatures' change through time due to microbial degradation processes. Representative numbers of the small blocks will be removed at the time of each of these subsequent annual SBP surveys, and following laboratory analysis to measure percent moisture content, this data will be used to assess comparative changes in timber density, at different burial depths, through time (Table 10.2)

Air-dried European Oak (Quercus robur), originally sourced from Poland, was provided to size by the Western Australian Museum (WAM) Conservation Department from left over timber used to build the 1999 replica Dutch ship Duyfken. Freshly sawn green pine (Pinus radiata) was purchased from a sawmill in the south-western of Western Australia, then cut to length. All sleepers were fabricated as a single beam, except where two and three beams were respectively vertically stacked with $7.5 \mathrm{~cm}$ gaps in between the timber beams (Fig. 10.2). Three pine sleepers were each cut into $16.5 \mathrm{~cm}$ lengths, each section then rotated through $90^{\circ}$ such that the end grain was vertical, then these were drilled and pinned using pine dowels and PVA timber glue to reform the $50 \mathrm{~cm}$ long vertical grain sleepers. Endplates for the sleepers and blocks were cut from inert $12 \mathrm{~mm}$ PVC sheeting, with dowel holes and slots drilled and cut to measure. These endplates were securely attached by driving two $25 \mathrm{~mm}$ diameter PVC dowels into slightly undersized drilled holes in the ends of each timber beam and block. The varying length of each PVC endplate, from the upper surface of the timber sleeper to the underside of the pre-cut slot, enabled accurate placement below the seabed and subsequent measurement of actual depth of sediment cover over the top face of the timber sleepers and blocks. Unique labels for each sleeper and block were engraved and blackened into the PVC endplates using a soldering iron and engraved colour-coded PVC cattle tags were also attached via nylon cable ties.

Burial of the sleepers adjacent to the James Matthews wreck site was achieved through diver-operated water dredging. Together with staff, the WAM Departments of Archaeology and Conservation provided their new dive and research vessel Dirk Hartog as surface support, including surface supplied air, SCUBA, water dredge and dive platform. Burial of the 38 pine and oak sleepers and blocks was accomplished in approximately $30 \mathrm{~h}$ of dive time, during 16 dives, over a 5-day period in mid-February 2017. An additional 18 dives were needed for site preparation, layout, recording and trialing prior to and following the dredging activities. Two $30-\mathrm{m}$ long pre-installed parallel measuring tapes, set $50 \mathrm{~cm}$ apart and tied off to permanently installed star pickets, guided the positioning of the sleepers in a straight line (the sleepers were buried at right angles to the tapes with each endplate touching one of the tapes). Blocks were installed in a grid with locations identified using two perpendicular tapes. Each sleeper/block hole was dredged by the diver operated suction 


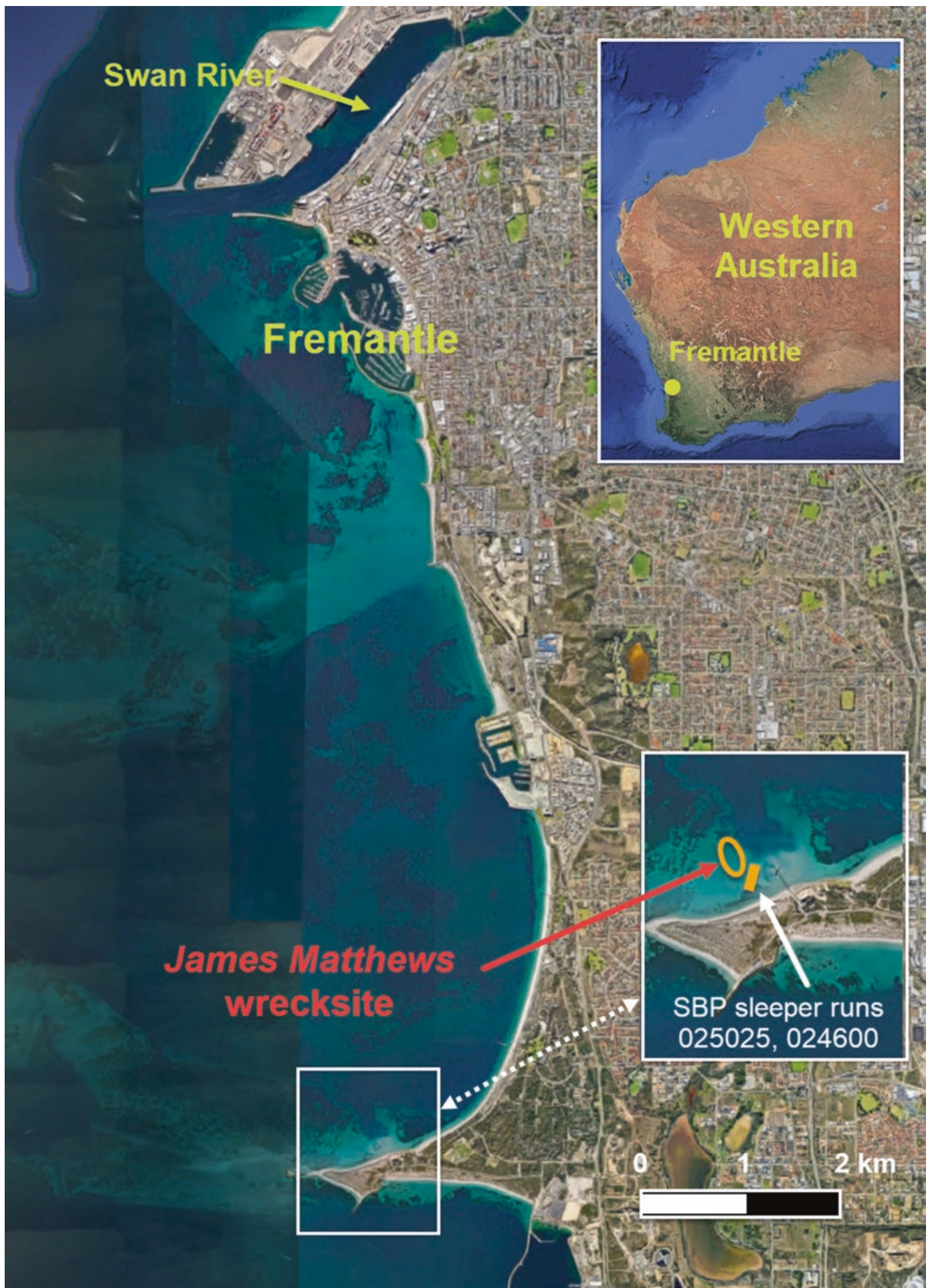

Fig. 10.1 Location map of the James Matthews wreck-site (Google Maps)

head until the required burial depth was achieved, with sand stockpiled on the side. Each sleeper/block was randomly selected from the vessel, additional temporary weights placed on the timber to overcome its natural buoyancy, swum to the seabed and a long flat plank inserted through the endplate slot/s. The sleeper/block was then placed in the dredged hole and if the horizontal plank rested on the natural seabed surface at both ends of the excavated hole, then the correct burial depth had been achieved. In this situation the dredge head was reversed, and the stockpiled sand dredged back into the 
Table 10.2 In situ experimental design

\begin{tabular}{|c|c|c|c|c|}
\hline Timber type & Burial depth & Grain orientation & Stacking & Sleeper/block \\
\hline \multirow[t]{5}{*}{ Pine } & $3 \times 10 \mathrm{~cm}, 3 \times 30 \mathrm{~cm}, 3 \times 50 \mathrm{~cm}$ & Horizontal & Single & Sleeper \\
\hline & $3 \times 30 \mathrm{~cm}$ & Vertical & Single & Sleeper \\
\hline & $1 \times(10+30 \mathrm{~cm})$ & \multirow{2}{*}{ Horizontal } & \multirow[t]{2}{*}{ Stacked } & \multirow[t]{2}{*}{ Sleeper } \\
\hline & $1 \times(10+30+50 \mathrm{~cm})$ & & & \\
\hline & $6 \times 10 \mathrm{~cm}, 6 \times 30 \mathrm{~cm}, 6 \times 50 \mathrm{~cm}$ & Vertical & Single & Block \\
\hline \multirow[t]{2}{*}{ Oak } & $3 \times 30 \mathrm{~cm}$ & Horizontal & Single & Sleeper \\
\hline & $3 \times 30 \mathrm{~cm}$ & Vertical & Single & Block \\
\hline \multirow[t]{2}{*}{ Jarrah $^{\mathrm{a}}$} & $3 \times 30 \mathrm{~cm}$ & Horizontal & Single & Sleeper \\
\hline & $3 \times 30 \mathrm{~cm}$ & Vertical & Single & Block \\
\hline
\end{tabular}

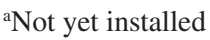

hole, burying the sleeper/block (Fig. 10.3). Temporary weights were progressively removed during the backfilling. Following completion of all dredge backfilling a weighted horticultural rake was used by an over-weighted diver to smooth seabed irregularities around each sleeper/block and to restore seabed levels to the underside of each endplate slot (Fig. 10.4). Table 10.3 lists the order and separation distances of all buried sleepers.

The Innomar SES-2000 compact SBP was selected for the sub-bottom measurements as it operates in very shallow coastal waters, from around $50 \mathrm{~cm}$ to $400 \mathrm{~m}$ water depths (Innomar 2018). It is designed to be pole mounted on a survey or autonomous vessel, forward of propeller wash to avoid acoustic noise; has a sampling ping rate of up to 40 pings/second and data acquisition rate of $70 \mathrm{kHz}$, allowing for high survey vessel speeds of $2 \mathrm{~m} / \mathrm{s}$; and a very narrow transmit beam width $(-3 \mathrm{~dB})$ of $\pm 2^{\circ}$ which in shallow water depths $(<2.8 \mathrm{~m})$ and for shallow $(<50 \mathrm{~cm})$ buried timbers results in an acoustic foot of $<10 \mathrm{~cm}$.

Field data collection occurred on 7 and 8 June 2017 using the Innomar SES-2000 compact SBP and associated SESWIN software, together with a Trimble POS MV Surfmaster GNSS G2 real time satellite positioning antenna and heave correction sensor (IMU) (Applanix 2018) mounted on the WAM's research vessel Dirk Hartog (Fig. 10.5). The SBP transducer head was positioned $50 \mathrm{~cm}$ below sea surface level. Offsets from each sensor mounting position relative to the center of the SBP transducer were recorded and included into the positioning calculations. Fugro Satellite Positioning Pty. Ltd. supplied Marinestar positioning solution which enabled real time position tracking to approximately $15-20 \mathrm{~cm}$ in both the horizontal $(\mathrm{x}, \mathrm{y})$ and vertical $(\mathrm{z})$ directions, and with post-processing, $2 \mathrm{~cm}$ accuracy in the horizontal and vertical position. Surface marker buoys were tethered at each end and midway along the $30 \mathrm{~m}$ long line of sleepers, and multiple measurement runs were made with the coxswain guided by the surface buoys.

\subsubsection{James Matthews Comparative In Situ Surveys}

The James Matthews was a copper-sheathed wooden snow brig of 107 tons, constructed with iron deck knees and assembled with copper and iron fasteners and wooden treenails. The significance and history of this ship, which was wrecked in 1841 on the northern side of Woodman Point, Western Australia (Fig. 10.1) is described by Henderson (2009). The wreck covers an area $26 \times 7 \mathrm{~m}$ and is mostly buried to a depth of 1.5-2.0 $\mathrm{m}$ in medium grained (phi $=1.5)$ calcareous sand with the starboard side preserved to the bulwarks by the sand cover (Richards 2001; Richards et al. 2009).

Following its discovery in July 1973, WAM undertook multiple maritime archaeological excavations on the James Matthews site between 1974 and 1977, and during the extensive 1975-1976 excavation, surveyed and recorded the entire remaining ship's structure using a 3D recording grid frame and plumblines (Baker and Henderson 1979; Henderson 1977). The relative $x, y$, and $z$ positions of almost 5000 points of interest were recorded by hand on underwater plastic film, from which a 2D scale plan was drawn. In 2000 a conservation survey was also undertaken by WAM (Richards 2001) and identified timber type and its degradation condition at six test trench locations. The original 1975-1976 survey data sheets, together with the conservation survey data, have recently been extracted from WAM's archives, digitized, converted into a point cloud of data and used to digitally reconstruct a 3D AutoCAD model of the buried shipwreck remains (Fig. 10.6).

The conversion into 3D digital format of the in situ remains of degraded and non-degraded timbers of the keel/keelson, ribs and planking (beech, white oak and elm, respectively), the concreted iron deck knees and iron bars, slate, timber (pine) cargo and stone ballast, provides an opportune baseline for comparative analyses with SBP data. In June 2017, immediately following the SBP survey of the buried sleepers adjacent 
Fig. 10.2 Single and multiple stacked timber sleepers, each

$50 \times 12.5 \times 12.5 \mathrm{~cm}$ in dimension, showing assembly for $50 \mathrm{~cm}$ burial depth (right) measured from top face of timber surface to underside of slot
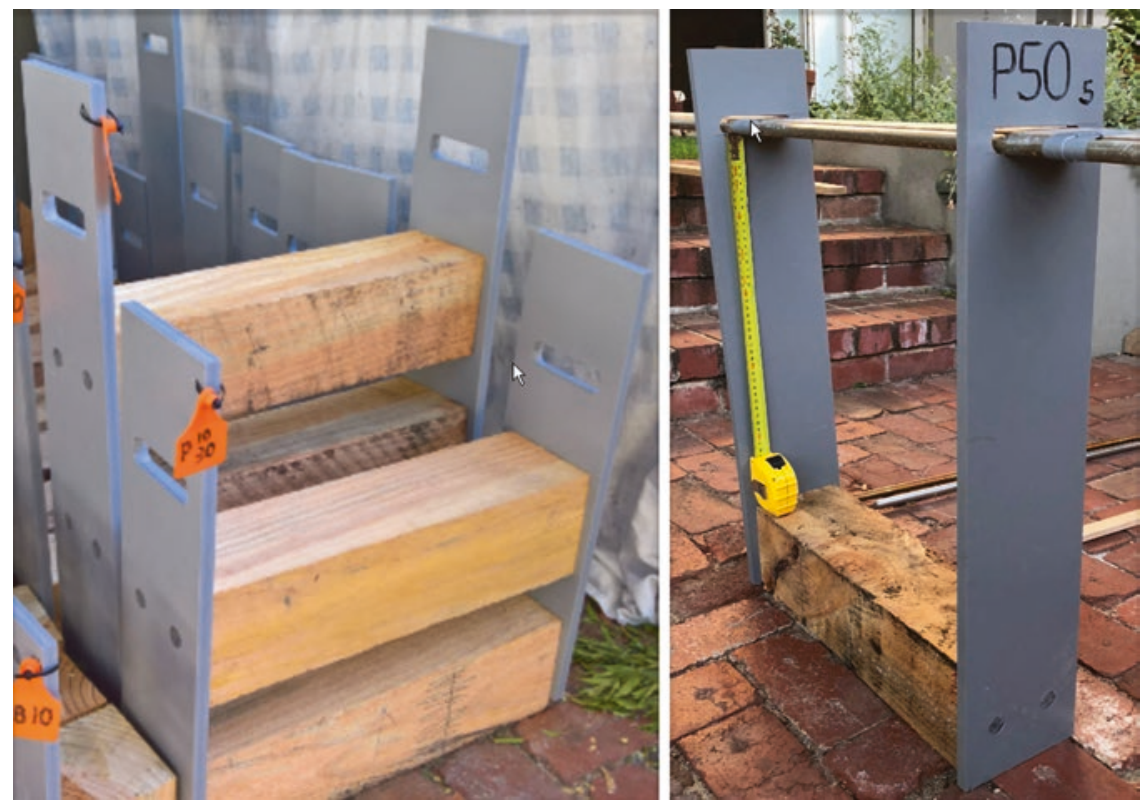

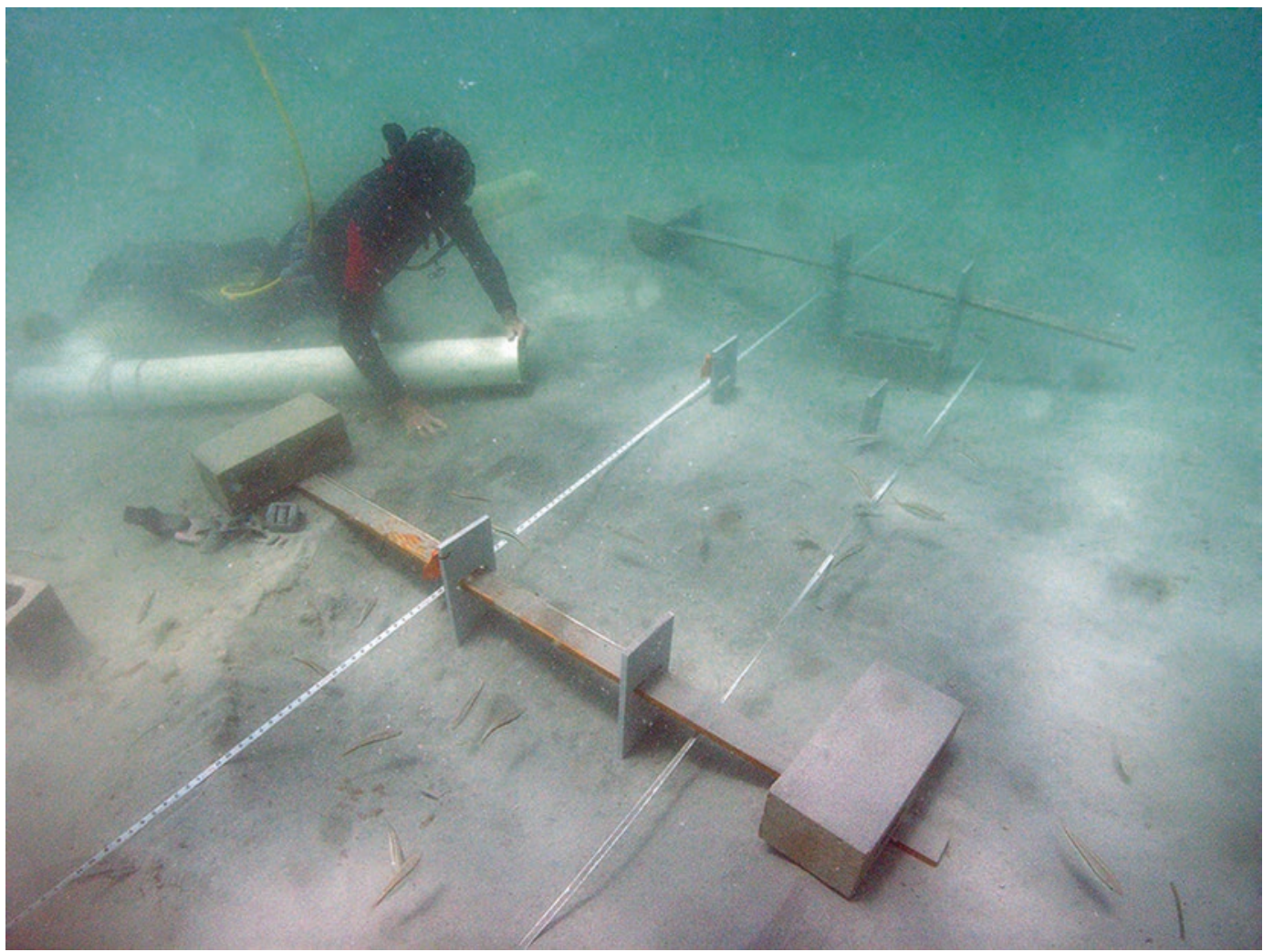

Fig. 10.3 Author burying timber sleepers (J. Carpenter, WAM)

to this wreck site, a total of 89 SBP transects (77 east-west and 12 north-south) were run with an average 1-m spacing across the James Matthews wreck-site (Fig. 10.7). These transects were collected using WAM's Dirk Hartog, traveling at an average speed of $2 \mathrm{~m} / \mathrm{s}$, with the same onboard SBP and real time positioning and motion correction equipment that was used to record the nearby buried sleepers. 


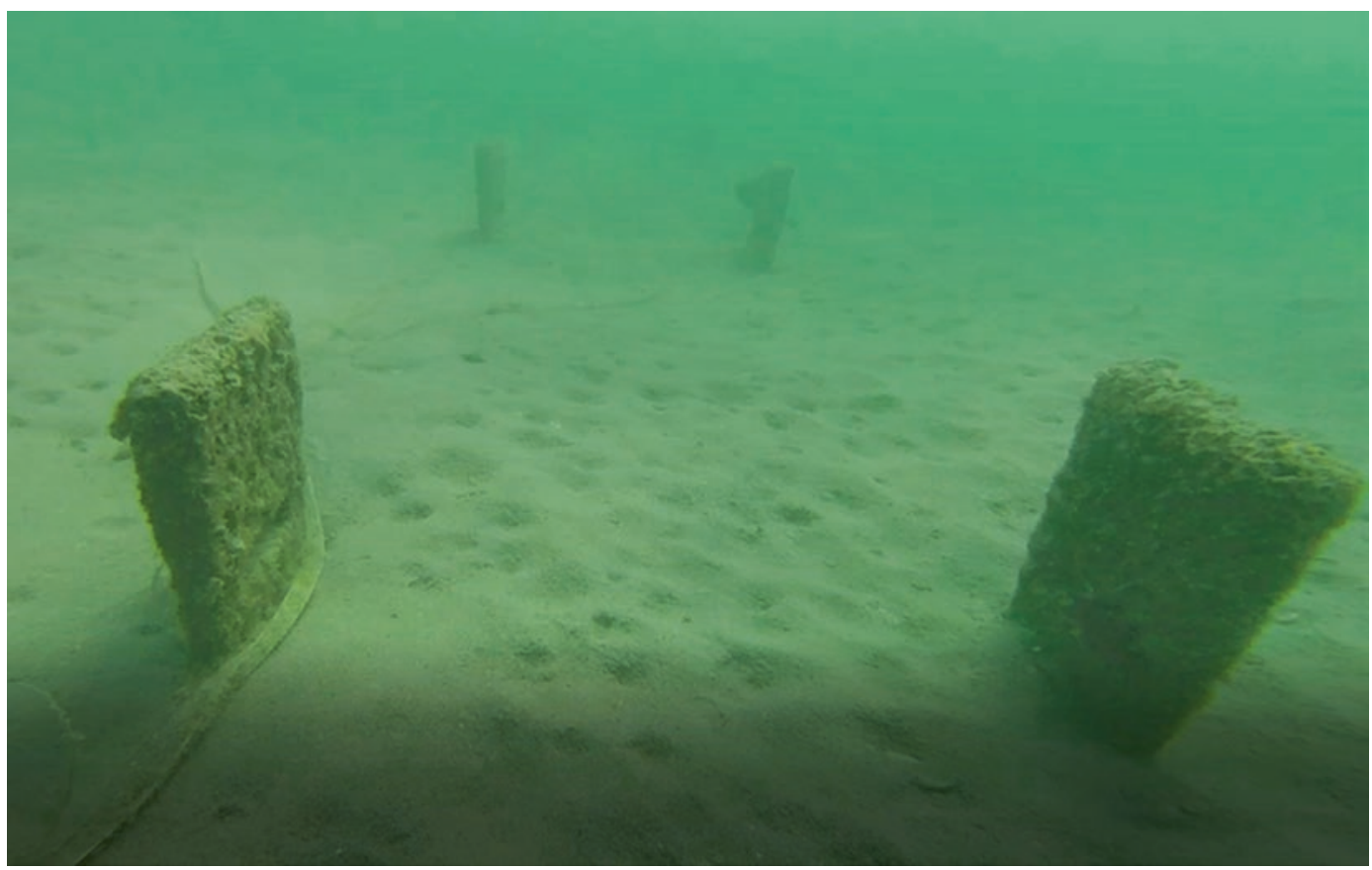

Fig. 10.4 Buried sleepers, 2 weeks after burial, showing endplates and slot (covered in growth) standing $50 \mathrm{~cm}$ apart above seabed

Table 10.3 Sleeper burial details

\begin{tabular}{|c|c|c|c|c|}
\hline $\begin{array}{l}\text { Sleeper } \\
\text { number }\end{array}$ & Sleeper ID & $\begin{array}{l}\text { Nominal } \\
\text { burial depth } \\
\text { (cm) }\end{array}$ & $\begin{array}{l}\text { Distance } \\
\text { from } \\
\text { northern } \\
\text { end }(\mathrm{m})\end{array}$ & $\begin{array}{l}\text { Actual burial depth } \\
\text { prior to SBP } \\
\text { measurements }(\mathrm{cm})\end{array}$ \\
\hline & $\begin{array}{l}\text { Star picket } \\
\text { (north) }\end{array}$ & & $\begin{array}{l}\text { Tape tied } \\
\text { off at } 0.5\end{array}$ & \\
\hline 1 & Pup30 & 30 & 4.2 & 28 \\
\hline 2 & P30 & 30 & 5.2 & 29 \\
\hline 3 & P30 & 30 & 6.55 & 27 \\
\hline 4 & P10 & 10 & 7.8 & 7 \\
\hline 5 & P50 & 50 & 8.85 & 41 \\
\hline 6 & P30 & 30 & 9.65 & 29 \\
\hline 7 & P10 & 10 & 10.76 & 10 \\
\hline 8 & O30 & 30 & 11.66 & 27 \\
\hline 9 & Pup30 & 30 & 12.76 & 28 \\
\hline 10 & O30 & 30 & 14.35 & 30 \\
\hline 11 & Pup30 & 30 & 15.10 & 30 \\
\hline 12 & P50 & 50 & 16.83 & 49 \\
\hline 13 & P50 & 50 & 17.75 & 45 \\
\hline 14 & O30 & 30 & 19.10 & 29 \\
\hline 15 & $\mathrm{P} 10 / 30$ & $10 / 30$ & 20.22 & 10 \\
\hline 16 & $\mathrm{P} 10 / 30 / 50$ & $10 / 30 / 50$ & 22.05 & 9 \\
\hline \multirow[t]{2}{*}{17} & P10 & 10 & 23.73 & 10 \\
\hline & $\begin{array}{l}\text { Star picket } \\
\text { (south) }\end{array}$ & & $\begin{array}{l}\text { Tape tied } \\
\text { off at } 29.9\end{array}$ & \\
\hline
\end{tabular}

Legend: P pine, O oak, Pup pine with vertical grain; 10/30/50-nominal burial depth $(\mathrm{cm})$

\subsection{Results and Discussion}

\subsubsection{In Situ Experimental Burial Survey}

Figure 10.8 depicts a typical annotated SBP echo plot (Innomar ISE2 software) approximately $20 \mathrm{~m}$ in length showing the collective acoustic traces recorded along the line of buried sleepers (A). These data were collected via vessel mounted transducer/receiver, and despite best efforts to maintain a central track within an accuracy of $\pm 25 \mathrm{~cm}$ along the full $30 \mathrm{~m}$ length of the buried sleepers, this southwestnortheast run mapped only the sleepers from approximately midway to the northern end, as identified by 'Besser Blocks' placed on the seabed at these two locations. Image (A) shows the raw echo plot without any post-processing of the acoustic data. The locations and depths of the buried sleepers are shown by the black hyperbolae (horseshoe shaped) lines. The lower image (B) shows the raw acoustic wave amplitude and phase of the individual acoustic Trace 271 through the water column and seabed (vertical scale exaggerated and plotted in Excel for greater visual clarity).

The SBP measures the two-way travel time taken for an emitted acoustic wave generated from the transmitter to travel through the water column and reflect from the seabed surface, and through the water column and sediment column to reflect 


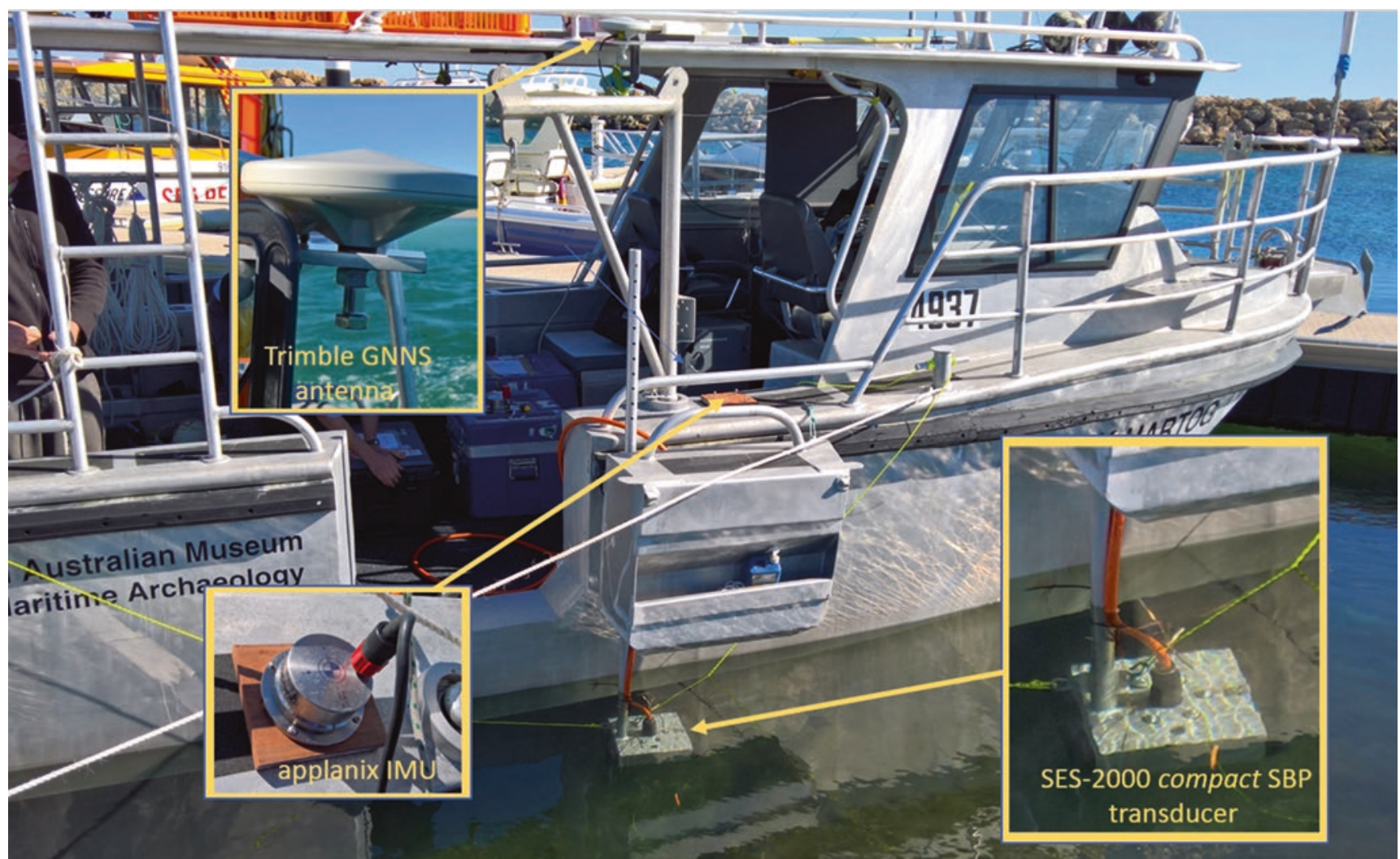

Fig. 10.5 WAM research vessel Dirk Hartog showing mounting locations of SES-2000 compact SBP transducer, Trimble GNSS antenna and applanix IMU sensors

from any buried reflector, and then return to the receiver head. Using a default setting for the speed of sound in water $(1500 \mathrm{~m} / \mathrm{s})$ the respective depths below the transmitter/ receiver (transducer) head are simply calculated by multiplying the sound velocity by $0.5 \times$ two-way travel time. For Trace 271 in Fig. 10.8, these correspond to 2.61 and $3.01 \mathrm{~m}$, respectively, resulting in a calculated $40.0 \mathrm{~cm}$ depth of burial (DoB). At the time of measurement, seawater temperature was $19^{\circ} \mathrm{C}$ and salinity $35 \mathrm{ppt}$ which would result in an actual speed of sound in seawater of $1517 \mathrm{~m} / \mathrm{s}$ (Lovett 1978). A sensitivity assessment of the variability in assumed/actual speed of sound in the water column indicated that the estimated depths of seabed and reflector surface buried up to $50 \mathrm{~cm}$ below the seabed would increase by $2-3 \mathrm{~cm}$. Despite these increases, the variability of the difference between the two simultaneous depth estimates (i.e. DoB) ranges only from 0 to $1 \mathrm{~cm}$ for reflector surfaces buried $10-50 \mathrm{~cm}$. However, the assumed speed of sound through the sediment column has a greater effect on DoB estimates. Based on Richards et al. (2009) characterization of the sediments over the adjacent James Matthews wreck site, a sediment velocity correction factor of 1.195 can be applied to the speed of sound in the water column. This correction factor was derived by Robb et al. (2005) from in situ measurements of the speed of sound in intertidal medium grained sands. An increase in the speed of sound in the sediment from 1500 to $1813 \mathrm{~m} / \mathrm{s}$ results in an increase in DoB of approximately $2-8.3 \mathrm{~cm}$ for sleepers buried $10-50 \mathrm{~cm}$.

Depths of burial for all identified buried reflectors were initially identified by the locations of hyperbolae from unprocessed SBP data in echo plot Runs 025025.RAW and 024600.RAW (Fig. 10.9) and their positions matched to the known locations of sleepers. At each of these locations the depth and amplitude values of the central and two adjacent traces on either side (at $2 \mathrm{~m} / \mathrm{s}$ vessel speed and 40 pings/s sampling frequency, a $12.5 \mathrm{~cm}$ wide sleeper would be theoretically insonified (hit) by three acoustic waves) were exported from the ISE software, tabulated into an Excel spreadsheet, then plotted (see Fig. 10.8b for one such trace). The seabed surface was determined as the depth corresponding to the zero intercept between the two maxima seabed amplitudes, and the depth of the upper surface of 
Fig. 10.6 Plan view (a) and expanded oblique stern view of remaining buried starboard hull (b) showing partially complete 3D digital model of the James Matthews

shipwreck remains with corresponding survey photos. Total length of buried remains is $26 \mathrm{~m}$ (a). Keelson and keel (dark browns); ceiling planking (tan); ribs (midbrown); outer planking (light grey); iron ballast and curved deck knees (blue); remaining slate mound (black); pine timber cargo (dull yellow) and 2000 test trench locations (bright yellow boxes). Excavation survey photos courtesy WAM (P. Baker, WAM)
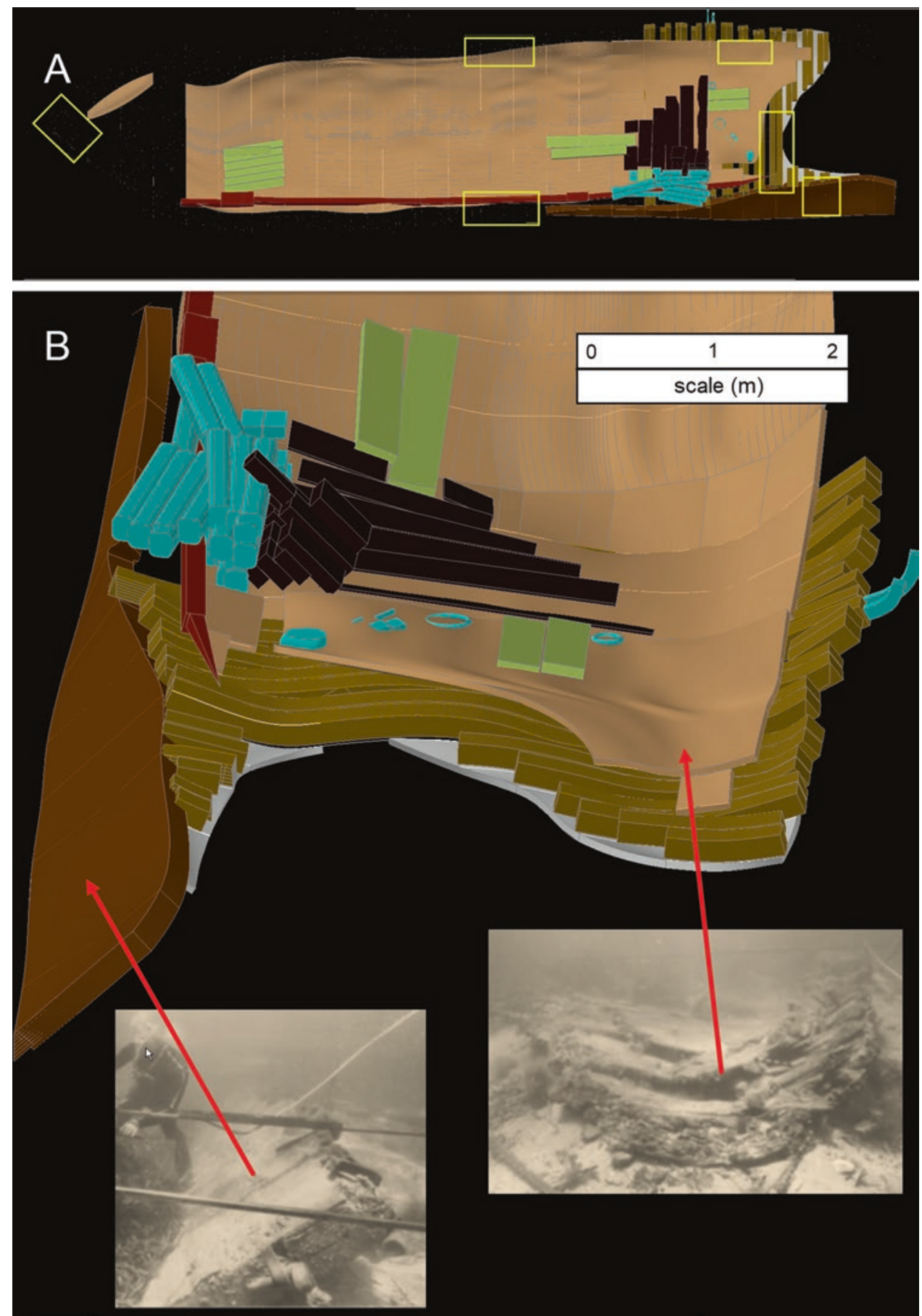

the buried sleepers were likewise determined at the zero intercept between the two maxima sediment/timber interface amplitudes. In Fig. 10.8b, these respectively correspond to -2.61 and $-3.01 \mathrm{~m}$ giving a recorded DoB of $40 \mathrm{~cm}$. The trace selected to best represent the central location of each buried sleeper was the one with the shallowest interface depth (corresponding to the most vertical radiated and reflected acoustic waves).

Actual sleeper burial depths were calculated by divers recording the average height of the endplate slots of each sleeper above/below seabed level. This distance was then subtracted from the known precise distance from the slot to each respective upper sleeper face. For example, trace 271 in Fig. 10.8 was recorded at the location of one of the pine (P50) sleepers, which was assembled with a $50 \mathrm{~cm}$ gap between the bottom face of the slot and the upper face of the timber. The average depth of the slot above the seabed for this sleeper was measured to be nine $\mathrm{cm}$ and hence the actual a depth of sediment cover was $41 \mathrm{~cm}$. Note that when initially buried, this sleeper 
Fig. 10.7 SBP track lines

collected over James

Matthews shipwreck site

collected on 7 June (red) and

8 June 2017 (blue)

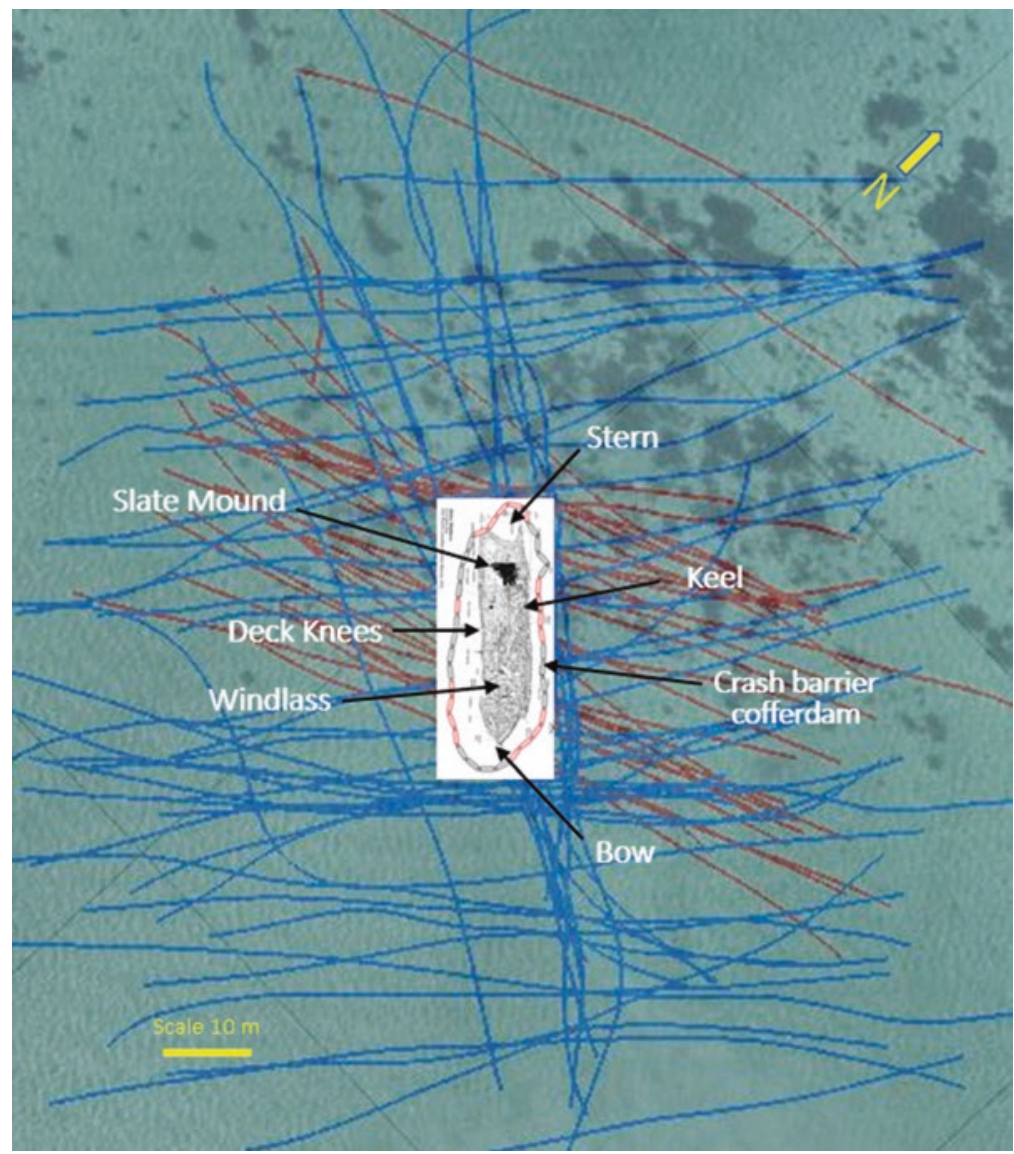

had a nominal $50 \mathrm{~cm}$ depth of burial (Table 10.3), however localized seabed erosion had subsequently scoured the surface and reduced the sleeper's actual depth of sediment cover.

The DoB results extracted from selected traces for each of 12 sleepers (three of which were measured on both runs) in echo plot Runs 025025.RAW and 024600.RAW were compared to diver measured actual burial depths using XLSTAT 2017.4 software to produce a scatter plot as shown in Fig. 10.9. This figure shows the variability in the 15 individual SBP estimates of DoB, and a linear trend line through this data. Uncorrected (for sediment velocity) SBP measurements are shown to: overestimate burial depths in very shallow $(7-10 \mathrm{~cm})$ sleeper burials by $3-7 \mathrm{~cm}$; underestimate burial depths in the mid $(26-40 \mathrm{~cm})$ burial depth range by $3-4 \mathrm{~cm}$; and underestimate (by $2-5 \mathrm{~cm}$ ) the measurement of the deepest $(50 \mathrm{~cm})$ burial depths. When the speed of sound is corrected to better represent the actual acoustic wave speed in the water column and up to $50 \mathrm{~cm}$ through the sediment, all estimates are increased by between 2 and $9 \mathrm{~cm}$ corresponding to burial depths $10-50 \mathrm{~cm}$, respectively. Following adjustments to the speed of sound, Fig. 10.9 shows that the SBP linear trend line is closer to the 1:1 relationship between estimated and actual burial depth, especially for sleepers buried deeper than $25-30 \mathrm{~cm}$.
The potential relationship between acoustic wave parameters and types and condition of a variety of buried material was assessed using the original reflection coefficient method by Warner (1990) and reworked in Plets et al. (2007). A reflection coefficient $\left(K_{R}\right)$ is the numerical expression for the strength of the reflection of the acoustic wave from a boundary (seabed surface, the interface between two sedimentary layers or a buried object) and relates to the ratio of the amount of energy reflected to the amount of energy transmitted across the boundary (Telford et al. 1990). A portion of the energy of acoustic sound waves reflect from a boundary if a contrast exists between the elastic properties (acoustic impedances) of the two media that form the boundary, and the remaining portion is transmitted across the boundary. The acoustic impedance of each media is simply the product of its density, $\rho$, and its compressional $\mathrm{P}$-wave velocity, $\mathrm{V}_{\mathrm{p}}$. In terms of the material properties of each media

$$
\mathrm{K}_{\mathrm{R}}=\left(\rho_{2} \mathrm{~V}_{\mathrm{p} 2}-\rho_{1} \mathrm{~V}_{\mathrm{p} 1}\right) /\left(\rho_{2} \mathrm{~V}_{\mathrm{p} 2}+\rho_{1} \mathrm{~V}_{\mathrm{p} 1}\right)
$$

In Appendix A of Plets et al. (2008) the reflection coefficient for a deeper reflector can be calculated based on acoustic trace properties and known/assumed compressional P-wave velocity values for sediment and the deeper (timber) reflector: 
$\mathrm{K}_{\mathrm{DR}}=\mathrm{A}_{\mathrm{DR}}\left[\mathrm{v}_{\mathrm{w}}\left(\mathrm{TWT}_{\mathrm{p}} / 2\right)+\mathrm{v}_{\mathrm{DR}}\left(\mathrm{TWT}_{\mathrm{DR}}-\mathrm{TWT}_{\mathrm{p}}\right) / 2\right] / \mathrm{x}$ (10.2)

where $\mathrm{x}$ is a calibration coefficient

$$
\mathrm{x}=\left[\mathrm{A}_{\mathrm{p}} \mathrm{v}_{\mathrm{w}}\left(\mathrm{TWT}_{\mathrm{p}} / 2\right)\right] / \mathrm{K}_{\mathrm{p}}
$$

and

$$
\mathrm{K}_{\mathrm{p}}=\left[\mathrm{A}_{\mathrm{m}} \mathrm{TWT}_{\mathrm{m}}\right] /\left[\mathrm{A}_{\mathrm{p}} \mathrm{TWT}_{\mathrm{p}}\right]
$$

$\mathrm{K}_{\mathrm{DR}}$ - reflection coefficient of deeper reflector

$\mathrm{K}_{\mathrm{p}}$ - reflection coefficient of primary (seabed) reflector

$\mathrm{v}_{\mathrm{DR}}-$ sound velocity in sediment

$\mathrm{v}_{\mathrm{w}}$ - sound velocity through water

$\mathrm{A}_{\mathrm{DR} / \mathrm{p} / \mathrm{m}}$ - amplitude of deeper reflector/seabed/seabed 1st multiple

$\mathrm{TWT}_{\mathrm{DR} / \mathrm{p} / \mathrm{m}}$ - two-way travel time to deeper reflector/seabed/ seabed 1st multiple

now, knowing

$\mathrm{TWT}_{\mathrm{DR} / \mathrm{p} / \mathrm{m}}=2 \mathrm{~d}_{\mathrm{DR} / \mathrm{p} / \mathrm{m}} / \mathrm{v}_{\mathrm{DR} / \mathrm{p} / \mathrm{w}}$

$\mathrm{d}_{\mathrm{DR}}-$ depth from seabed surface to deeper reflector

$\mathrm{d}_{\mathrm{p}}$ - depth from water surface to seabed

$\mathrm{v}_{\mathrm{p}}=\mathrm{v}_{\mathrm{w}}=1517 \mathrm{~m} / \mathrm{s}$ and $\mathrm{v}_{\mathrm{DR}}=1813 \mathrm{~m} / \mathrm{s}$

and $\mathrm{TWT}_{\mathrm{DR}}-\mathrm{TWT}_{\mathrm{p}}$ is TWT in seabed $=2 \mathrm{~d}_{\mathrm{DR}} / \mathrm{v}_{\mathrm{DR}}$

then by substituting (10.4) into (10.3)

$$
\mathrm{x}=\left[\mathrm{A}_{\mathrm{p}}{ }^{2} \mathrm{~d}_{\mathrm{p}}^{2}\right] /\left[\mathrm{A}_{\mathrm{m}} \mathrm{d}_{\mathrm{m}}\right]
$$

whereby Eq. (10.2) simplifies to:

$$
\mathrm{K}_{\mathrm{DR}}=\mathrm{A}_{\mathrm{DR}}\left[\mathrm{d}_{\mathrm{DR}}+\mathrm{d}_{\mathrm{p}}\right] / \mathrm{x}
$$

Amplitudes for the seabed, deeper reflector and seabed first multiple, together with their respective depths were tabulated from the Excel plots created for each buried sleeper identified in Sect. 10.4.1 above, as well as at locations away from the buried sleepers. Tabulated amplitude and depth data for the seabed and first seabed multiple at 39 trace locations away from the sleepers were used in Eq. (10.5) to calculate individual $\mathrm{x}$ values. The calibration factor $\mathrm{x}(1,500,000)$ was calculated as the 50th percentile from the combined frequency distribution derived from the 39 individual $\mathrm{x}$ values (Fig. 10.10) as per Plets et al. (2007).

Reflection coefficients for all sleepers identified in Runs 025025.RAW and 024600.RAW were then calculated using Eq. (10.6) and are shown as a scatter plot in Fig. 10.11. This plot shows identification and separation of buried sleepers by timber type, with little influence by their burial depth. It also shows that grain orientation (pine horizontal vs pine vertical) is not a strong influence on in situ SBP acoustic wave form

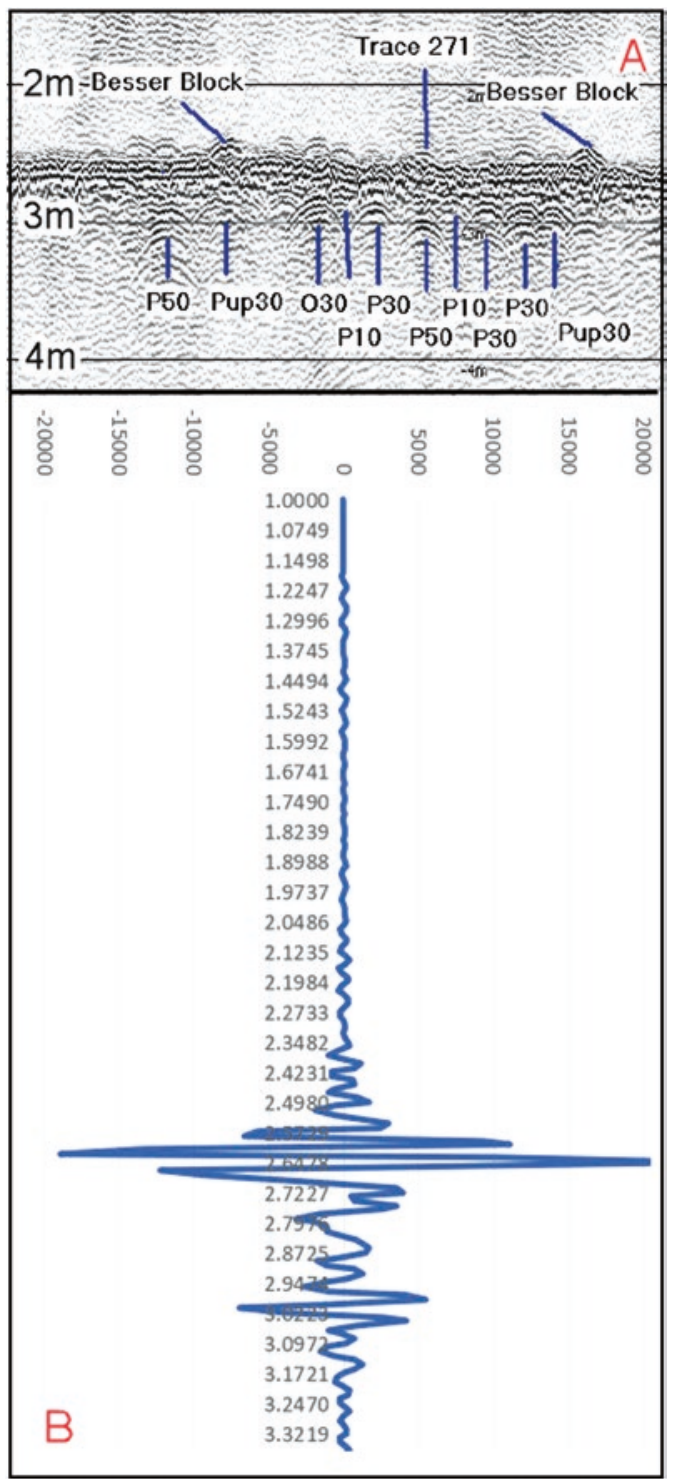

Fig. 10.8 SBP Echo plot 025024.RAW showing unprocessed curtain data recorded at $12 \mathrm{kHz}$ in a SW-NE direction along the line of buried sleepers each buried approximately $1 \mathrm{~m}$ apart (a) and individual echo Trace 271 plotted in Excel (b). Horizontal distance shown in (a) is $19.4 \mathrm{~m}$ and horizontal black lines show depths in meter increments. Horizontal scale in (b) is wave amplitude, vertical scale is meters below transducer head: seabed surface is at $-2.61 \mathrm{~m}$ and top sleeper interface is at $-3.01 \mathrm{~m}$

measurements as they cannot be separated in the scatter plot. There was uncertainty associated with identification of a sleeper along Run 0246000.RAW. It was tentatively identified as an oak sleeper $(\mathrm{O}$ ?) with a nominal burial depth of $30 \mathrm{~cm}$. This same sleeper was identified as oak on Run 025025.RAW. The reflection coefficient for the sleeper on Run 025025.RAW is consistent with the reflection coefficient value for the other confirmed oak sleeper, while the reflection coefficient for uncertain sleeper on Run 0246000. RAW matched those from other pine sleepers. This suggests 


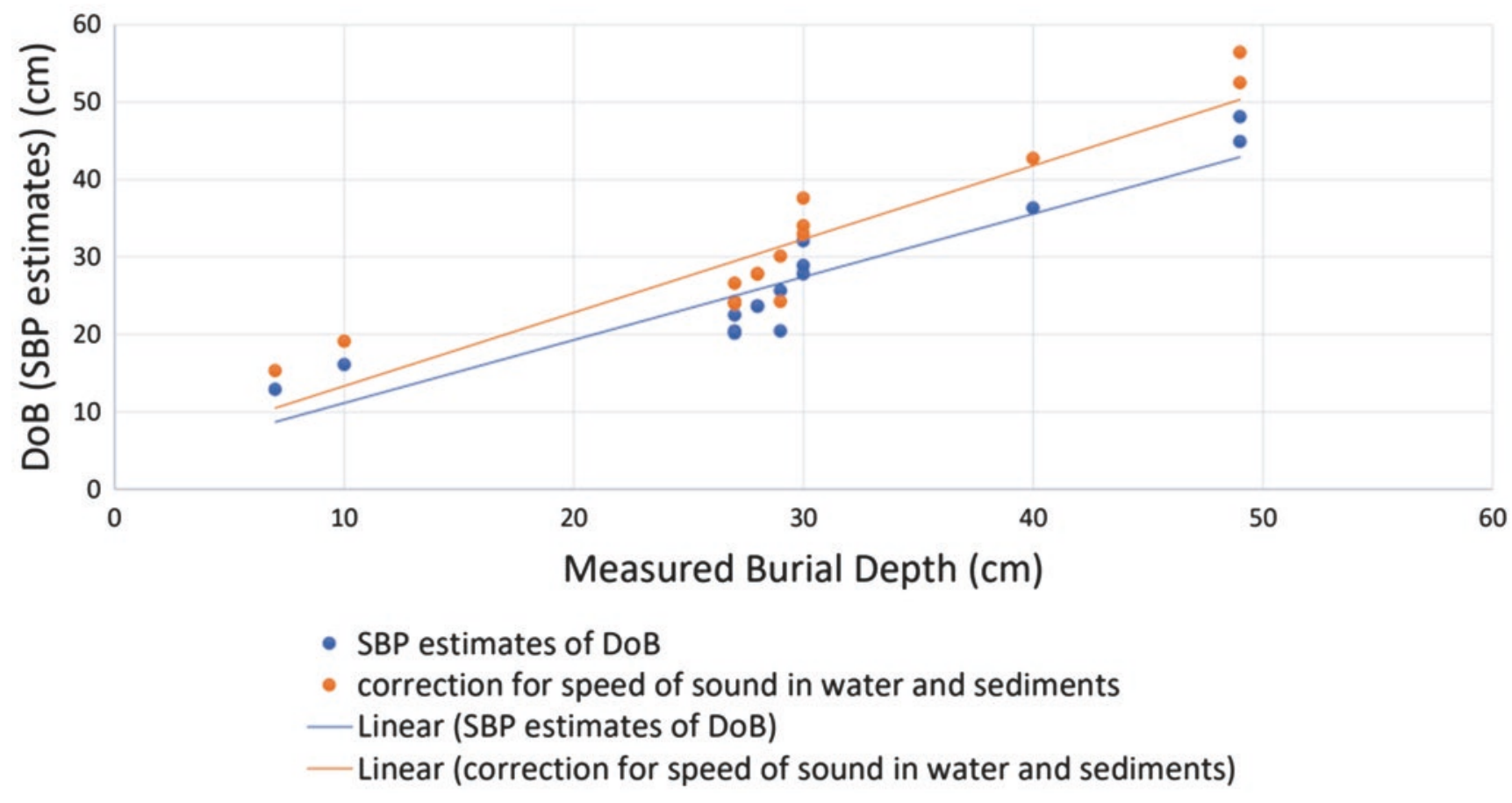

Fig. 10.9 Scatter plot of sleeper burial depths measured by SBP vs actual burial depths

Fig. 10.10 Relative frequency distribution for calibration factor $\mathrm{x}$

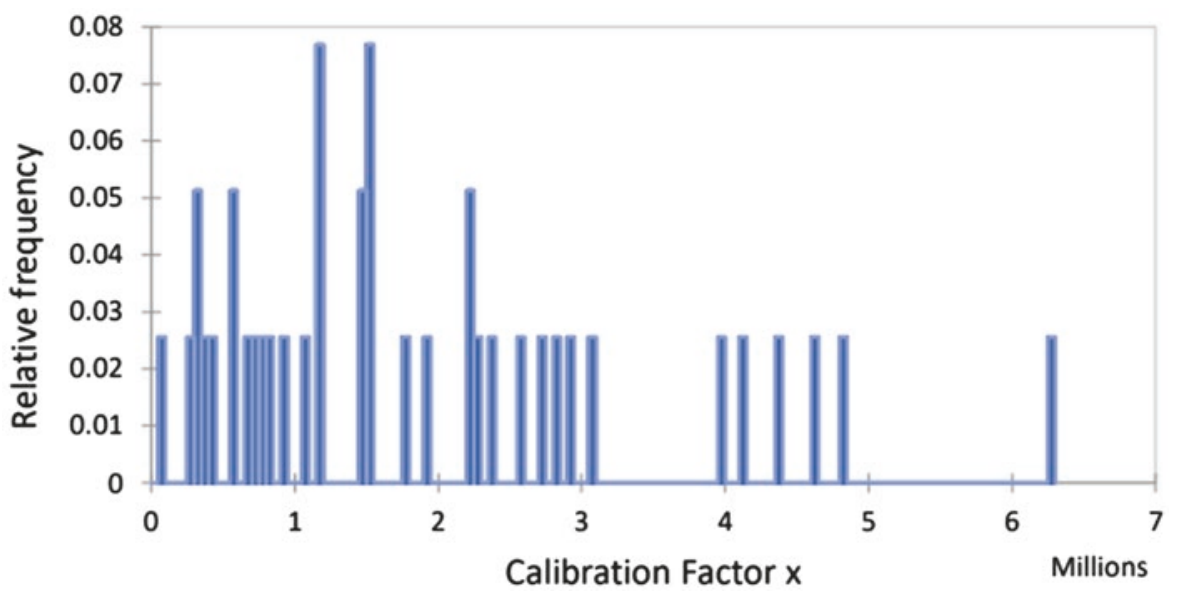

that the tentative identification of the sleeper may have been wrong. The reflection coefficient for one nominal $30 \mathrm{~cm}$ deep pine sleeper was higher than those from the oak sleepers, and this may also have resulted from an incorrect sleeper identification, or possibly from partial insonification or nonhomogeneous sediment cover.

While the calculated reflection coefficient for each buried sleeper shows promise as a means of identifying different buried material types, the magnitude of these values (c. 0.038 oak and 0.013 for pine) appear to be low compared with previous field and theoretical results (Arnott et al. 2005; Plets et al. 2009). As can be seen by Eq. (10.1), $K_{D R}$ values approach zero when the acoustic impedance for each layer are similar (Eq. 10.7). Changes in value of either the density $(\rho)$ of sediment or timber and/or the assumed compressional acoustic wave speed $\left(\mathrm{v}_{\mathrm{p}}\right)$ in the sediment or timber can significantly change the absolute magnitude of the derived reflection coefficient.

$$
\rho_{\text {timber }} \mathrm{v}_{\text {ptimber }}=\rho_{\text {sediment }} \mathrm{v}_{\text {psediment }}
$$

In the early work by Quinn et al. (1997c) reflection coefficients were calculated for a range of sediment types (sand, sand-silt-clay, clay) and for 11 different timbers using known densities and theoretical velocity values. Sediment densities ranged from 2100 to $1450 \mathrm{~kg} / \mathrm{m}^{3}$ and corresponding velocity values ranged from 1734 to $1496 \mathrm{~m} / \mathrm{s}$. Timber 


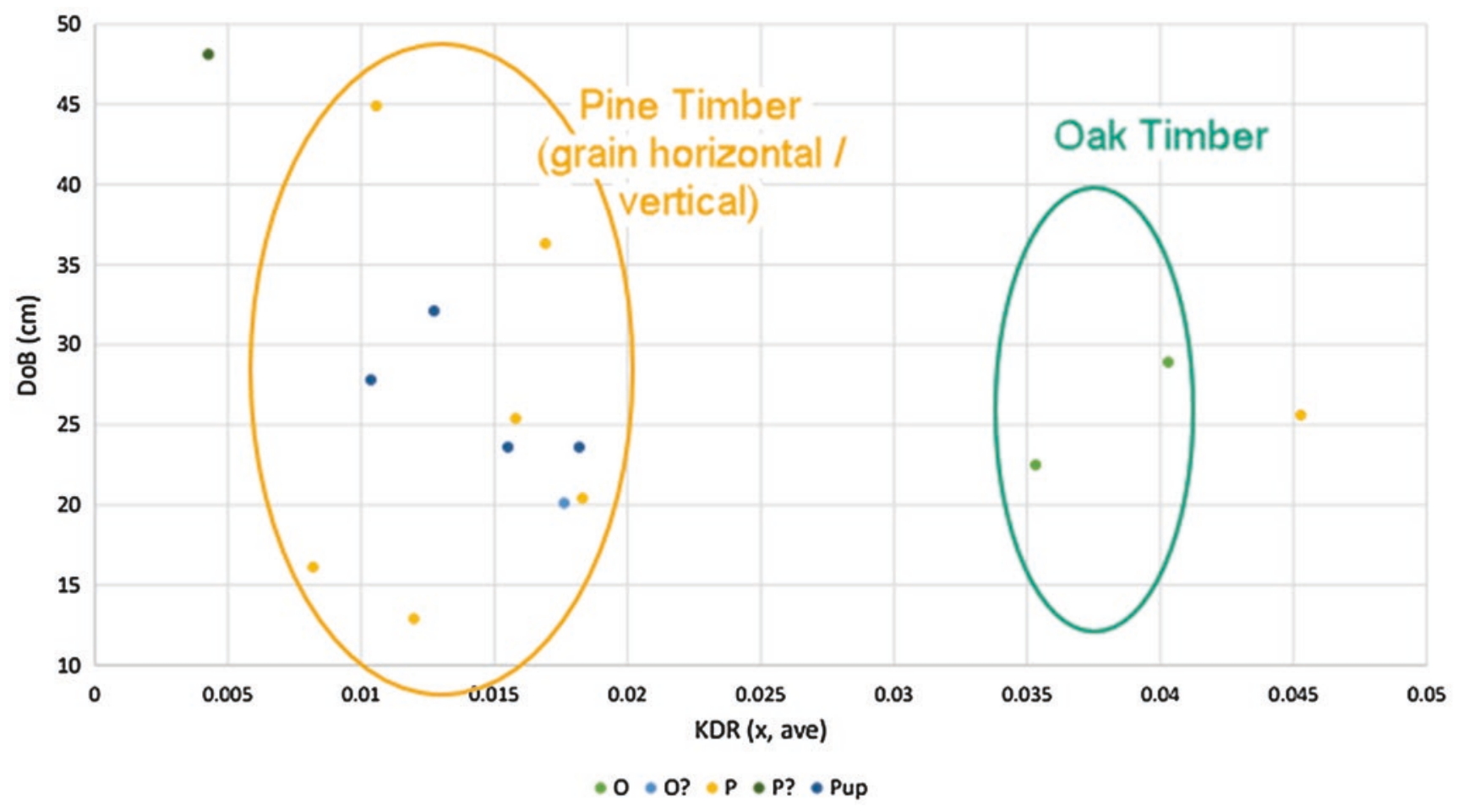

Fig. 10.11 Scatter plot of calculated reflection coefficients against depth of burial

densities for oak and Scotts pine were 660 and $580 \mathrm{~kg} / \mathrm{m}^{3}$, respectively, and theoretical $\mathrm{v}_{\mathrm{p} \text { timber }}$ values ranged from 3120 to $1230 \mathrm{~m} / \mathrm{s}$ (oak) and 6010 to $1000 \mathrm{~m} / \mathrm{s}$ (Scotts pine) for longitudinal, radial and tangential grain orientations. Theoretical reflection coefficients calculated for oak in sand ranged from -0.28 to -0.47 (longitudinal-radial) and in clay from -0.03 to 0.25 . Likewise, for Scotts pine and other softwoods, reflection coefficients ranged from $<0.02$ to $<0.25$. Dix et al. (2001) demonstrated that the timber density values used in this earlier work were based on air dried values and did not represent timber in its fully saturated state. This difference results in a $25-43 \%$ reduction in the timber's compressional wave speeds, and consequently, for reflection coefficients. For example, the $\mathrm{K}_{\mathrm{DR}}$ values for saturated oak in sand reduce from -0.28 to -0.04 (longitudinal) and from -0.47 to -0.31 (radial).

Arnott et al. (2005) explored the theoretical relationships between timber degradation and reflection coefficients by exposing oak and pine in seawater for durations up to 9 months and by laboratory measurements of density and compressional wave velocities in those timbers with different states of degradation. The authors plotted (in Fig. 10.2a) theoretical $K_{R}$ values against timber density ranging from 280 to $580 \mathrm{~kg} / \mathrm{m}^{3}$ for highly degraded-undegraded oak in sand, sand-silt-clay and clay sediments based on tangential and radial velocity measurements in the timber. Extrapolating this linear relationship for higher oak densities from 630 and $700 \mathrm{~kg} / \mathrm{m}^{3}$ would result in theoretical $\mathrm{K}_{\mathrm{R}}$ (radial and tangen- tial) values ranging from -0.045 to 0.04 in sand. Similarly, theoretical $K_{R}$ relationships were derived for highly degraded-undegraded pine (densities $165-525 \mathrm{~kg} / \mathrm{m}^{3}$ ) however a non-linear relationship was established. With lower water temperatures, Arnott et al. (2005) used 1522 and $1734 \mathrm{~m} / \mathrm{s}$ for compressional wave speeds in water and sand, respectively, and the same sediment densities as used by Quinn et al. (1997b).

In situ derivation of $K_{R}$ values were undertaken by Plets et al. $(2007,2009)$ through interpretation of Chirp data collected on Grace Dieu (1439), River Hamble, UK. The remaining timbers at this site are heavily degraded oak, and the sediments are fine silts (phi $=4.7$ ). Compressional wave velocities used were 1484 and $1517 \mathrm{~m} / \mathrm{s}$ for water and sediments, respectively, and sediment density calculated as $1766 \mathrm{~kg} / \mathrm{m}^{3}$. Derived $\mathrm{K}_{\mathrm{R}}$ (radial and tangential) values for timbers in the wreck ranged from 0.07 to 0.19 .

Presently the only estimated $K_{R}$ values for timbers in sand are derived from theoretical analyses using laboratory derived $v_{p}$ timber values for fresh and degraded oak and pine samples. In the current study green Radiata pine and fully fire-dried oak was used for the sleepers with SBP measurements made 3 months after burial. The density of green Radiata pine is around $1000 \mathrm{~kg} / \mathrm{m}^{3}$ (Forest Products Commission 2018) and the average bulk density of the oak timber was measured to be $642(\mathrm{n}=6$, range $579-751) \mathrm{kg} / \mathrm{m}^{3}$ using the method by Grattan (1987). The extent to which the moisture content of these buried timbers increased from the 
time of burial to the time of SBP measurement is currently unknown, but it is likely that they would still be higher than the densities used in the analyses by Arnott et al. (2005). Consequently, the extrapolated $\mathrm{K}_{\mathrm{R}}$ (radial and tangential) values (ranging from -0.045 to 0.40 for oak densities 630 $700 \mathrm{~kg} / \mathrm{m}^{3}$ ) may be reasonably indicative for the timber at the time of measurement. In addition, due to the manner of water dredge backfilling, the sand density covering the sleepers may have been substantially lower than the surrounding undisturbed sediments (identified recently when the author noticed significant reduction in penetration resistance to driving in sediment cores) which would also affect the acoustic impedance of the sand covering the sleepers.

\subsubsection{James Matthews Comparative In Situ Wreck-Site Surveys}

SBP track lines over the James Matthews shipwreck site have previously been shown in Fig. 10.7, using QPS Fledermaus software ver7.7.6.628, together with the 2D plan of the 1976 James Matthews excavation survey. Full analyses (i.e. quantitative comparison of SBP trace information and geo-located survey data, together with quasi-3D visualization of all track data) have yet to be completed, but indicative interpretations on several lines have been made. Figure 10.12 shows the longitudinal profile of the buried wreck remains from bow to stern and the unprocessed raw echo plot. The vertical distance between the horizontal black lines on this plot is $1 \mathrm{~m}$. The top of the continuous (horizontal) red/black/ red line represents the seabed surface, and the bright outer red hyperbolae (horseshoe) reflectors, sitting approximately $1 \mathrm{~m}$ above the seabed and $30 \mathrm{~m}$ apart on the left and righthand sides of the echo plot, depict plastic road crash barriers installed as a cofferdam in December 2013 by WAM as part of the in situ management plan (Richards et al. 2014; Winton and Richards 2005). This figure also depicts one single vertical wave Trace (1154), recorded forward of the slate mound, showing two major reflectors: the top reflector being the seabed surface $(-2.57 \mathrm{~m})$ and $0.53 \mathrm{~m}$ below this is the upper face of the ship timbers. Below the upper face of the timbers are several more weaker reflectors, most likely additional timber interfaces. Overall this echo plot depicts the upper longitudinal surface (ranging from -2.57 to $-2.94 \mathrm{~m}$ ) and depth of burial $(10-53 \mathrm{~cm})$, and possibly the lower limit of buried reflectors $(-2.85$ to $-3.4 \mathrm{~m})$, associated with the remains of the James Matthews shipwreck.

Figure 10.13 depicts transverse echo plots from the deck knees to the keel (left to right) across the slate mound and amidships. Trace 1506 through the slate mound (with its upper surface at $-2.0 \mathrm{~m}$ sitting $70-75 \mathrm{~cm}$ above the seabed) shows that nearly all the acoustic wave energy is reflected from the top $45 \mathrm{~cm}$ of the slate, with very little energy propa- gating through to lower levels (below $-2.45 \mathrm{~m}$ ). By contrast with Trace 1412, which is closer to the deck knees and clear of slate, there are strong multiple reflectors located at depth (from around -3.0 to $-3.6 \mathrm{~m}$, possibly representing hull timbers). This indicates that the slate is reflecting most acoustic energy and there is an acoustic shadow below the mound where hull timbers were not recorded. The WAM excavation survey also recorded iron bars laying between the slate mound and the keel and like the slate mound, the acoustic wave energy is strongly reflected from this area with little propagation below. Trace 688 at the amidships location, forward of the slate mound, similarly shows multiple reflectors from just below the seabed surface to $-3.3 \mathrm{~m}$, probably representing ship's timbers and timber cargo.

The indicative interpretations from the James Matthews SBP data runs provide insight into the depth of sediment cover, the total burial depth and potentially different material types associated with the archaeological remains at this site. Further detailed analyses will provide quantitative analyses of sediment thicknesses and ship hull form. Also, the different reflection characteristics qualitatively assessed from slate, iron and timber suggest that the reflection coefficient method applied to the buried sleepers may equally be applicable to characterize different material/timber types and states of degradation on the shipwreck site.

\subsection{Future Surveys and Analyses}

Further sleeper burials at the current and at a finer-grained site are planned to complete the experimental design. Sleepers must be buried in fine sediments to enable comparison of results with those buried in the coarser sands at the James Matthews site. They must be constructed from an Australian hardwood (Jarrah, which was used in Australian colonial period shipbuilding (O'Reilly 2007; Pemberton 1979; Staniforth and Shefi 2014), and need to be buried at both sites to compliment the European timbers (oak and pine). Those already buried at the James Matthews site allow comparative analyses of derived reflection coefficients. Oak sleepers need to be buried at 10 and $50 \mathrm{~cm}$ at the James Matthews site to better assess the depth related relationships with derived reflection coefficients. Iron plates need to be buried at both sites to asses accuracy and variability of measurement of buried iron associated with iron used in ship construction and carried as cargo. Following completion of the installation of these new sleepers, both sites need to be fully surveyed using the same SBP equipment. In addition, further SBP surveys are planned 1,2 and possibly 5 years after burial to detect any possible influence of biological degradation on acoustic reflection measurements.

All future SBP surveys at both sites will be accomplished using a purpose-developed, wheel-based underwater trans- 


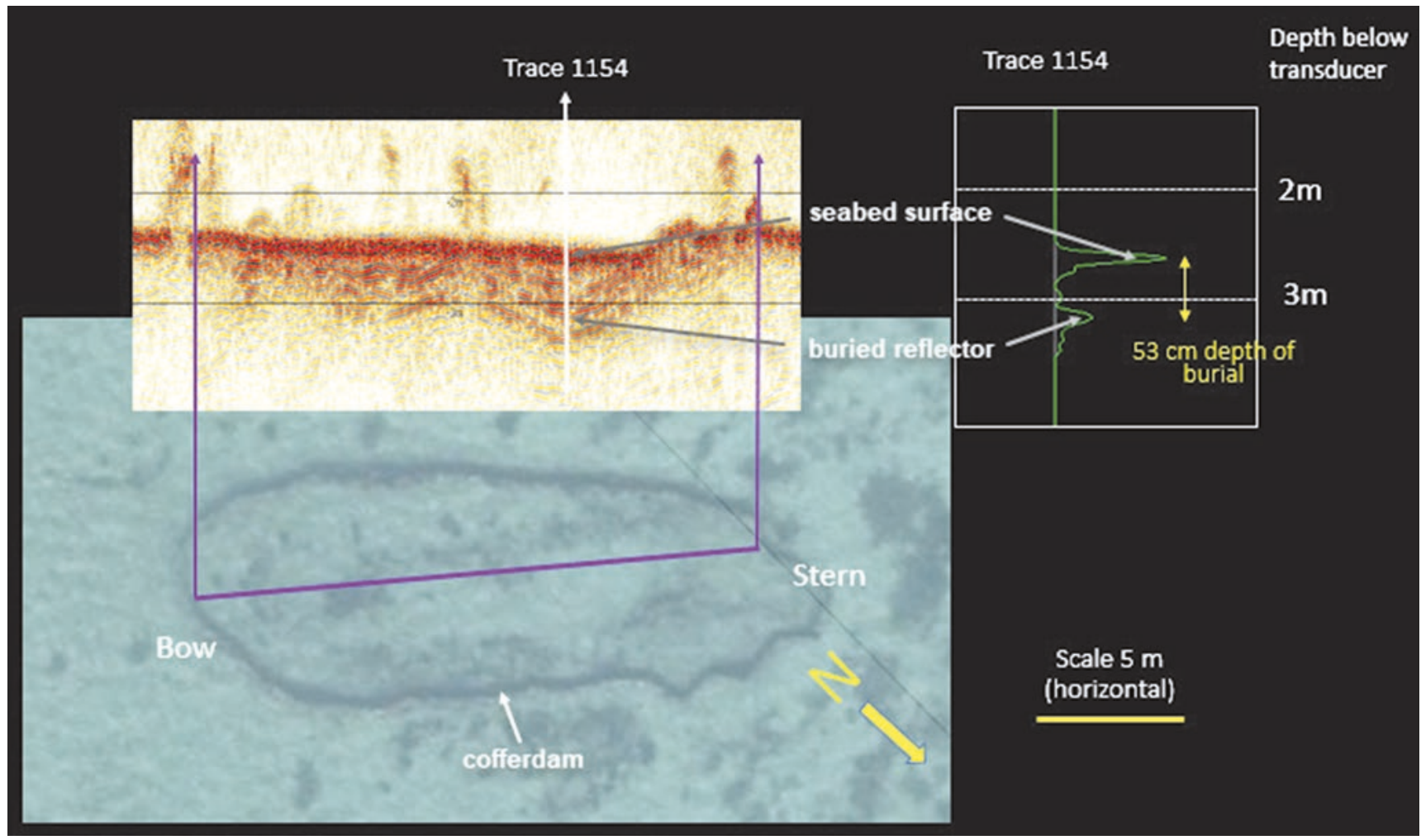

Fig. 10.12 SBP echo curtain data from bow to stern of buried remains of James Matthews. Amplitude peaks in Trace 1154 show a buried reflector $53 \mathrm{~cm}$ below seabed surface

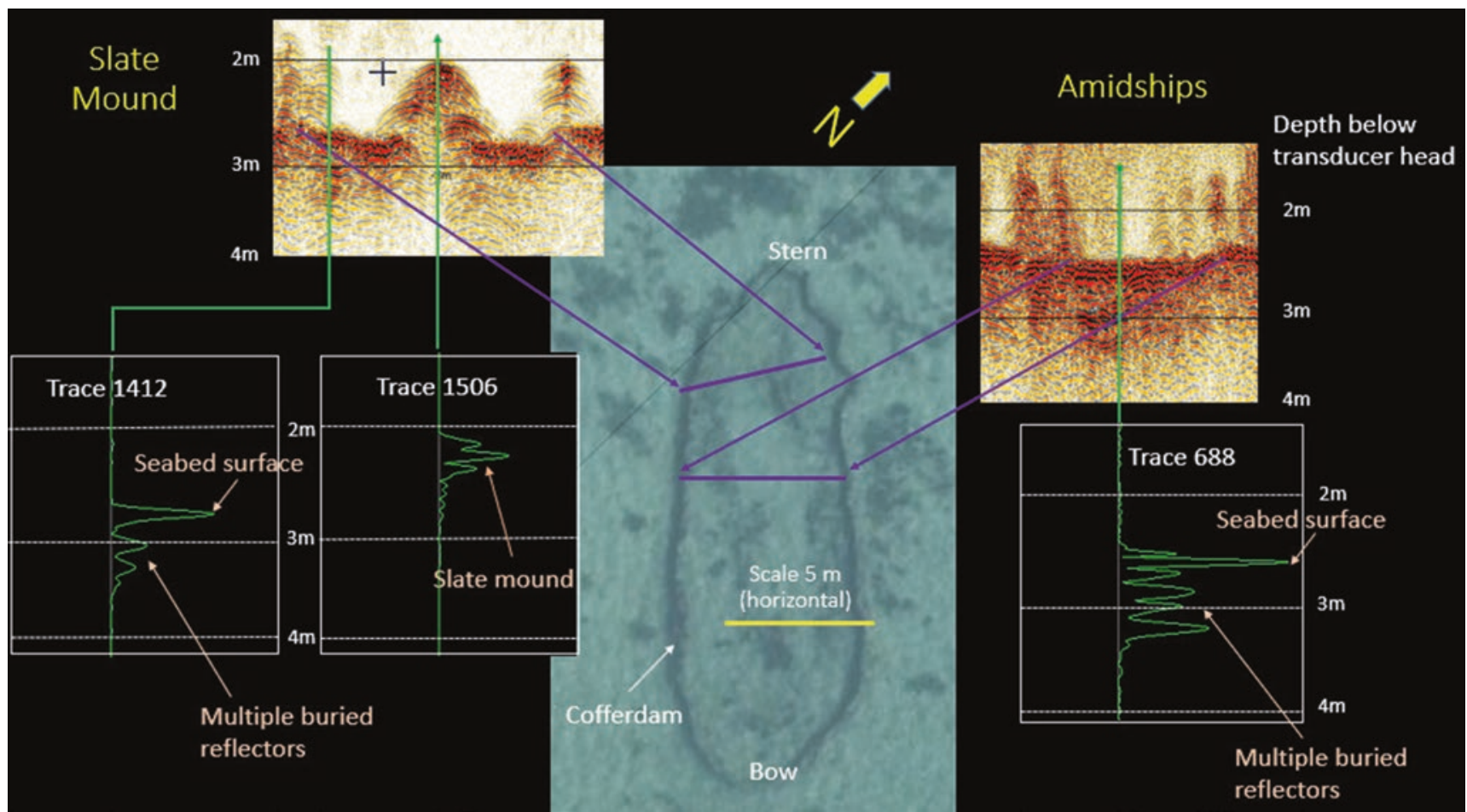

Fig. 10.13 SBP echo curtain data across the slate mound and amidships locations over James Matthews. Amplitude response in Trace 1506 (top of slate mound) shows little evidence of deeper reflectors (most acoustic energy absorbed/reflected by slate) compared to Trace
1412, where multiple peaks at depth show buried reflectors. Likewise Trace 688 shows evidence of multiple stacked buried reflectors (most likely timber cargo and hull structure) amidships, forward of the slate mound 
ducer sled with a mast mounted RTK GPS sensor, which will be pulled along the seabed to ensure highly controlled positioning of the transducer head relative to each sleeper. Multiple runs back and forth will be undertaken to obtain sufficient measurement data to permit statistical analyses of the accuracy, precision and Type I and II error estimates associated with the measurement of depth of sediment cover, and the variability associated with reflection coefficient estimates.

To assess the confidence in the magnitude of reflection coefficient estimates from the acoustic data, timber samples which were simultaneously buried alongside their respective sleepers will be recovered at the time of each future SBP survey and analysed for bulk and conventional density, percent moisture content and depth of degradation. Replicated sediment cores collected from reference and backfilled locations on both sites will be analysed for in situ and bulk density, grain size distribution and pore water dissolved oxygen, $\mathrm{pH}$ and redox potential.

To translate the quantitative measurement performance of the parametric SBP from the individual buried sleeper environment to a complex buried shipwreck site, the direct comparison of the SBP measured data and the corresponding archaeological survey results from the James Matthews site is planned. Once the local survey coordinates from the original 1976 archaeological excavation survey and constructed 3D digital model of the James Matthews wreck-site are transformed to the WGS 84 navigational coordinate system, then SBP predicted and actual measured depth locations, reflector surfaces and material identified will be assessed. This will provide quantitative evaluation of sediment thickness (DoB) and hull form in 2D profiles, and interpretation in quasi-3D format using gridding and visualization software.

\subsection{Conclusions}

The proof of concept survey provided initial quantification of accuracy and variability associated with non-invasive parametric SBP measurements of shallow buried maritime archaeological material. The in situ experimental component measured the depth of burial of shallow-buried oak and pine timber beams ('sleepers') at different burial depths (10, 30 and $50 \mathrm{~cm}$ ) with different grain orientations in coarse sediments using the Innomar parametric SES-2000 compact SBP. A linear trendline between sediment and water velocity corrected SBP predictions versus actual measured depth of burial slightly over-estimates (by $1-3 \mathrm{~cm}$ ) the $1: 1$ relationship between estimated and actual burial depth. Variability of individual corrected SBP estimates around the linear trendline was $1-6 \mathrm{~cm}$. For three sleepers detected in multiple runs, a difference of up to four $\mathrm{cm}$ was identified between runs. Statistical analysis of the variability in individual trace mea- surements for all sleeper burials will be undertaken with greater confidence once a second set of SBP measurements are undertaken at two sites (different sediment characteristics), with a full set of replicated multi-timber and iron sleeper types at three burial depths, and with a greater control over position of SBP measurements.

Interpretation of SBP survey data recorded from these buried sleepers also identified reflection coefficient relationships between acoustic wave parameters and buried timber, but not with timber grain orientation. The acoustic reflection coefficient signatures, derived from the individual SBP acoustic wave reflections from the seabed surface and from the sleepers with different timber types and grain orientations, were used to identify material type. A scatter plot of depth of burial vs reflection coefficients shows discrimination of material type (pine timber versus oak timber). Within the limitations of currently available data, the scatterplot results suggest that the ability to identify material type from SBP measurements may possibly be independent of burial depth. It also shows that grain orientation (pine horizontal vs pine vertical) does not have a strong influence on in situ SBP acoustic wave form measurements as grain orientation cannot be separated in the scatter plot. However, the magnitude of these derived reflection coefficients is very low (c. 0.038 for oak and 0.013 for pine) and lower than theoretical values calculated by others based on laboratory measurements of the speed of sound through oak and pine timbers. The calculation of reflection coefficients is sensitive to the acoustic impedance properties of the reflector interface (i.e. the density and speed of sound through the overlying sediment and buried timber) and their values used in this study appear to be quite different to and beyond the range previously tested. No conclusive statement can be made regarding the representativeness of the $K_{R}$ values derived to date in this study, but in situ sediment and timber impedance data will be collected as part of ongoing studies to improve confidence in the results.

Interpretation of SBP measurements over the buried shipwreck material at the James Matthews wreck-site demonstrated a proven ability to undertake a non-invasive approach to record depth of sediment cover, the total burial depth and potentially different material types associated with the archaeological remains. The James Matthews shipwreck site has been fully excavated, archaeologically recorded and then reburied by maritime archaeologists from the Western Australian Museum in the mid-1970s. A 2D plan from that survey was used to identify key features on selected SBP runs. Different reflection characteristics from known locations of slate, iron and timber suggest that the reflection coefficient method applied to the buried sleepers may equally be applicable to characterize different material types and states of degradation on the shipwreck site. 
While still ongoing, this research demonstrates that parametric SBPs can be used for in situ management purposes and the critical quantification of shallow buried archaeological material between 10 and $50+\mathrm{cm}$. Further confidence in the measurement accuracy and variance estimates and ability to differentiate material types will be achieved following planned additional sleeper burials and repeated measurements in both fine and coarse-grained sediments, as well as direct 3D spatial comparison with recorded shipwreck material. In combination with other geophysical search tools, these parametric SBP results also reveal the importance of, and opportunity associated with, 3D recording and interpretation of buried maritime archaeological material.

Acknowledgments Special thanks and my fullest appreciation are extended to all staff from the Departments of Maritime Archaeology and Conservation, WAM, and especially to Adjunct Associate Professor Jeremy Green, Adjunct Professor Mike (Mack) McCarthy and Vicky Richards, for their encouragement, personal support in the field and conservation laboratory, and provision of vessels together with diving and dredging equipment. Thanks also to those volunteer members from MAAWA who helped with the diving and other field activities. Special thanks also to Dr. Doug Bergersen, MD Acoustic Imaging Pty Ltd. who provided the Innomar SES-2000 compact SBP and SESWIN acquisition software, the GNSS G2 navigational sensors and software, and provided his time to support field data measurements. I would like to acknowledge Fugro Satellite Positioning Pty Ltd. who supplied their Marinestar positioning solution to improve GNSS G2 real time positioning data, and thank Innomar Technologie GmbH and QPS b.v. for the numerous technical discussions and the provision of their respective ISE2 V29533 and Fledermaus ver7.7.6.628 software packages. Lastly, I would also like to thank the anonymous peer reviewers whose comments helped to improve the quality of this chapter.

\section{References}

Applanix (2018) POS MV Datasheet. https://www.applanix.com/downloads/products/specs/posmv/ POS-MV-.pdf. Accessed 27 Aug 2018

Arnott S, Dix J, Best A, Gregory D (2005) Imaging of buried archaeological materials: the reflection properties of archaeological wood. Mar Geophys Res 26(2):135-144

Baker P, Henderson G (1979) James Matthews excavation. A second interim report. Int J Naut Archaeol 8(3):225-244

Bergstrand T, Godfrey N (2007) Reburial and analyses of archaeological remains: studies on the effect of reburial on archaeological materials performed in Marstrand, Sweden 2002-2005. The RAAR project

Björdal CG, Daniel G, Nilsson T (2000) Depth of burial, an important factor in controlling bacterial decay of waterlogged archaeological poles. Int Biodeterior Biodegrad 45(1-2):15-26. https://doi. org/10.1016/S0964-8305(00)00035-4

Bjørnø L (2017a) Finite-amplitude waves. In: Neighbors T, Bradley D (eds) Applied underwater acoustics. Elsevier, Amsterdam, pp 857-888

Bjørnø L (2017b) Sonar Systems. In: Neighbors T, Bradley D (eds) Applied underwater acoustics. Elsevier, Amsterdam, pp 587-742

Bjørnø L (2017c) Underwater acoustic measurements and their applications. In: Neighbors T, Bradley D (eds) Applied underwater acoustics. Elsevier, Amsterdam, pp 889-947
Bull JM, Quinn R, Dix JK (1998) Reflection coefficient calculation from marine high resolution seismic reflection (Chirp) data and application to an archaeological case study. Mar Geophys Res 20(1):1-11

Bull JM, Gutowski M, Dix JK, Henstock TJ, Hogarth P, Leighton TG, White PR (2005) Design of a 3D Chirp sub-bottom imaging system. Mar Geophys Res 26(2-4):157-169

Caiti A, Bergem O, Debedal J (1999) Parametric sonars for seafloor characterization. Meas Sci Technol 10:1105-1115

Cvikel D, Grøn O, Boldreel LO (2017) Detecting the Ma'agan Mikhael B shipwreck. Underw Technol 34(2):93-98. https://doi.org/10.3723/ ut.34.093

Dix JK, Arnott S, Best AI, Gregory D (2001) The acoustic characteristics of marine archaeological wood. In: Leighton TG, Heald GJ, Griffiths H, Griffiths G (eds) Acoustical oceanography 23(2):299306. Institute of Acoustics, St Albans, UK

Dix JK, Bastos A, Plets R, Bull J, Henstock T (2008) High resolution sonar for the archaeological investigation of marine aggregate deposits. Project Report, vol 3365

Forest Products Commission WA (2018) Radiata pine. https://www.fpc. wa.gov.au/node/906. Accessed 27 Aug 2018

Forrest J, Homer J, Hooper G (2005) The application of acoustic remote sensing to maritime archaeological site surveys. AIMA Bull $29: 1-8$

Grattan DW (1987) Waterlogged wood. In: Pearson C (ed) Conservation of marine archaeological objects. Butterworths, London

Gregory D (1998) Re-burial of timbers in the marine environment as a means of their long-term storage: experimental studies in Lynaes Sands, Denmark. Int J Naut Archaeol 27(4):343-358. https://doi. org/10.1111/j.1095-9270.1998.tb00814.x

Gregory D (2007) Environmental monitoring: reburial and analysis of archaeological remains. Studies on the effects of reburial on archaeological materials performed in Marstrand, Sweden 2002-2005. In: Bergstrand T, Godfrey IN (eds) The RAAR Project. Bohuslans Museums, Uddevalla, pp 59-90

Gregory D, Matthiesen H (2012) Nydam Mose: in situ preservation at work. Conserv Manag Archaeol Sites 14(1-4):479-486. https://doi. org/10.1179/1350503312Z.00000000041

Grøn O, Boldreel LO (2013) Sub-bottom profiling for large-scale maritime archaeological survey: an experience-based approach. OCEANS, Bergen, Norway, 10-14 June 2013, MTS/IEEE. In: Paper presented at the OCEANS 2013 MTS/IEEE Bergen: The Challenges of the Northern Dimension. https://doi.org/10.1109/ OCEANS-Bergen.2013.6608027

Grøn O, Boldreel LO, Cvikel D, Hermand JP (2015) Subbottom profiling in shallow water: the Akko 4 test case. Rio Acoustics 2015 IEEE/OES Acoustics in Underwater Geosciences Symposium, Rio de Janeiro, Brazil, 29-31 July 2015. https://doi.org/10.1109/ RIOAcoustics.2015.7473611

Gutowski M, Malgorn J, Vardy M (2015) 3D sub-bottom profilinghigh resolution 3D imaging of shallow subsurface structures and buried objects. MTS/IEEE OCEANS 2015 Genova: Discovering Sustainable Ocean Energy for a New World, Genoa, Italy, 18-21 May 2015. https://doi.org/10.1109/OCEANS-Genova.2015.7271468

Henderson G (1977) Four seasons of excavation on the James Matthews wreck. First southern hemisphere conference on maritime archaeology, Fremantle

Henderson G (2009) Redemption of a slave ship: the James Matthews. Western Australian Museum, Welshpool

Innomar (2018) Innomar SES-2000 compact Sub-Bottom Profiler fact sheet. https:// www.innomar. com/ses2000compact.php. Accessed 10 Sept 2018

Kozaczka E, Grelowska G, Kozaczka S, Szymczak W (2013) Detection of objects buried in the sea bottom with the use of parametric echosounder. Arch Acoust 38(1):99-104 
Lafferty B, Quinn R, Breen C (2006) A side-scan sonar and highresolution Chirp sub-bottom profile study of the natural and anthropogenic sedimentary record of Lower Lough Erne, northwestern Ireland. J Archaeol Sci 33(6):756-766. https://doi.org/10.1016/j. jas.2005.10.007

Lawrence MJ, Bates CR (2001) Acoustic ground discrimination techniques for submerged archaeological site investigation. Mar Technol Soc J 35(4):65-73. https://doi.org/10.4031/002533201788058053

Lovett JR (1978) Merged seawater sound-speed equations. Acoust Soc Am 63(6):1713-1718. https://doi.org/10.1121/1.381909

Manders M, Gregory D, Richards V (2008) The in situ preservation of archaeological sites underwater. an evaluation of some techniques. In: May M, Jones M, Mitchell J (eds) Proceedings of the 2nd heritage, microbiology and science, microbes, monuments and maritime materials conference, 28 June-1 July 2005. RSC Publishing, London, pp 179-203

Mindell DA, Bingham B (2001) A high-frequency, narrow-beam sub bottom profiler for archaeological application. In: Paper presented at the IEEE Oceans 2001, Honolulu

Missiaen T (2010) The potential of seismic imaging in marine archaeological site investigations. Relicta 6:219-236

Missiaen T, Wardell N, Dix J (2005) Subsurface imaging and sediment characterisation in shallow water environments-introduction to the special volume. Mar Geophys Res 26(2):83-85

Missiaen T, Slob E, Donselaar ME (2008) Comparing different shallow geophysical methods in a tidal estuary, Verdronken Land van Saeftinge, Western Scheldt, the Netherlands. Neth J Geosci Geol Mijnb 87(2):151-164

Missiaen T, Demerre I, Verrijken V (2012) Integrated assessment of the buried wreck site of the Dutch East Indiaman 't Vliegent Hart. Relicta 9:191-208

Missiaen T, Evangelinos D, Claerhout C, De Clercq M, Pieters M, Demerre I (2017) Archaeological prospection of the nearshore and intertidal area using ultra-high resolution marine acoustic techniques: results from a test study on the Belgian coast at OstendRaversijde. Geoarchaeology 1-15

Müller S, Wunderlich J (2003) Detection of embedded objects using parametric sub-bottom profilers. Int Hydrogr Rev 4(3):76-82

Müller S, Wunderlich J, Hümbs P, Erdmann S (2005) High-resolution sub-bottom profiling for the "shallow survey" common data set using the parametric echosounder SES-2000. In: Paper presented at the Shallow Survey 2005 4th International conference, Plymouth, 12-15 September 2005

O'Reilly R (2007) Australian built wooden sailing vessels of the South Australian intrastate trade. Flinders University, Maritime Archaeology Monograph Series 5, Adelaide

Ortmann N, McKinnon JF, Richards V (2010) In situ preservation and storage: practitioner attitudes and behaviours. AIMA Bull 34:27-44

Pemberton B (1979) Australian coastal shipping. Melbourne University Press, Carlton

Plets RMK, Dix JK, Adams JR, Best AI, Mindell DA (2005) High resolution acoustic imagery from a shallow archaeological site: the Grace Dieu-a case study. In: Proceedings of the international conference Underwater Acoustic Measurements: Technologies \& Results, Heraklion

Plets RMK, Dix JK, Best AI (2007) Mapping of the buried Yarmouth Roads wreck, Isle of Wight, UK, using a Chirp SubBottom Profiler. Int J Naut Archaeol 37(2):360-373. https://doi. org/10.1111/j.1095-9270.2007.00176.x

Plets RMK, Dix JK, Adams JR, Best AI (2008) 3D reconstruction of a shallow archaeological site from high-resolution acoustic imagery: the Grace Dieu. Appl Acoust 69(5):399-411

Plets RMK, Dix JK, Adams JR, Bull JM, Henstock TJ, Gutowski M, Best AI (2009) The use of a high-resolution 3D Chirp sub-bottom profiler for the reconstruction of the shallow water archaeological site of the Grace Dieu (1439), River Hamble, UK. J Archaeol Sci 36(2):408-418. https://doi.org/10.1016/j.jas.2008.09.026

Quinn R (2012) Acoustic remote sensing in maritime archaeology. In: Catsambis A, Ford B, Hamilton DL (eds) The Oxford handbook of maritime archaeology. Oxford University Press, Oxford, pp 68-89. https://doi.org/10.1093/oxfordhb/9780199336005.013.0003

Quinn R, Bull JM, Dix JK (1997a) Buried scour marks as indicators of palaeo-current direction at the Mary Rose wreck site. Mar Geol 140(3-4):405-413

Quinn R, Bull JM, Dix JK (1997b) Imaging wooden artefacts using Chirp sources. Archaeol Prospect 4(1):25-35

Quinn R, Bull JM, Dix JK, Adams JR (1997c) The Mary Rose sitegeophysical evidence for palaeo-scour marks. Int J Naut Archaeol 26(1):3-16. https://doi.org/10.1111/j.1095-9270.1997.tb01309.x

Quinn R, Adams JR, Dix JK, Bull JM (1998a) The Invincible (1758) site-an integrated geophysical assessment. Int J Naut Archaeol 27(2):126-138. $\quad$ https://doi.org/10.1111/j.1095-9270.1998. tb00796.x

Quinn R, Bull JM, Dix JK (1998b) Optimal processing of marine high-resolution seismic reflection (Chirp) data. Mar Geophys Res 20(1):13-20

Quinn R, Breen C, Forsythe W, Barton K, Rooney S, O'Hara D (2002) Integrated geophysical surveys of the French frigate La Surveillante (1797), Bantry Bay, Co. Cork, Ireland. J Archaeol Sci 29(4):413422. https://doi.org/10.1006/jasc.2002.0732

Richards V (2001) James Matthews (1841) conservation predisturbance survey report. Department of Materials Conservation, Western Australian Museum, Fremantle

Richards V (2011a) In situ preservation-application of a processbased approach to the management of underwater cultural heritage. Asia-Pacific Regional Conference on Underwater Cultural Heritage, Manila

Richards V (2011b) In situ preservation and reburial of the ex-slave ship James Matthews. AICCM Bull 32(1):33-43

Richards V, Godfrey IM, Blanchette RA, Held B, Gregory DJ, Reed E (2009) In situ monitoring and stabilisation of the James Matthews shipwreck site. In: Proceedings of the 10th ICOM Group on Wet Organic Archaeological Materials conference, Amsterdam

Richards V, MacLeod I, Veth P (2014) The Australian Historic Shipwreck Preservation Project-in situ preservation and long-term monitoring of the Clarence (1850) and James Matthews (1841) shipwreck sites. In: Proceedings of the 2nd Asia-Pacific Regional conference on Underwater Cultural Heritage, Honolulu, Hawaii, 13-16 May 2014

Robb GBN, Dix JK, Best AI, Bull JM, Leighton TG, White PR, Seal A (2005) The compressional wave and physical properties of inter-tidal marine sediments. Underwater Acoustic Measurements: Technologies \& Results, Heraklion

Shefi D, Veth P (2015) A critical analysis and philosophical review of 'rapid reburial': the Clarence project. Int J Naut Archaeol 44(2):371-381. https://doi.org/10.1111/1095-9270.12105

Staniforth M, Shefi D (2014) Shipbuilding in the Australian Colonies before 1850. 2014 ACUA Underwater Archaeology proceedings

Stewart DJ (1999) Formation processes affecting submerged archaeological sites: an overview. Geoarchaeology Int J 14(6):565-587

Telford WM, Geldart LP, Sheriff RE (1990) Applied geophysics, 2nd edn. Cambridge University Press, Cambridge

UNESCO (2001) UNESCO Convention on the Protection of the Underwater Cultural Heritage. http://www.unesco.org/new/en/ culture/themes/underwater-cultural-heritage/2001-convention/

Vardy ME, Dix JK, Henstock TJ, Bull JM, Gutowski M (2008) Decimeter-resolution 3D seismic volume in shallow water: a case study in small-object detection. Geophysics 73(2):B33-B40 
Vasudevan M, Sivakholundu KM, Venkata Rao D, Kathiroli S (2006) Application of parametric acoustics for shallow-water near-surface geophysical investigations. Oceans 2006-Asia Pacific

Von Deimling JS, Held P, Feldens P, Wilken D (2016) Effects of using inclined parametric echosounding on sub-bottom acoustic imaging and advances in buried object detection. Geo-Marine Letters: 1-7

Warner M (1990) Absolute reflection coefficients from deep seismic reflections. Tectonophysics 173:15-23

Wheeler AJ (2002) Environmental controls on shipwreck preservation: the Irish context. J Archaeol Sci 29(10):1149-1159. https://doi. org/10.1006/jasc. 2001.0762

Winton T (2015) Understanding the interactive nature of in situ processes for management of submerged cultural heritage material. AIMA Bull 39:71-83

Winton T, Richards V (2005) In situ containment of sediment for shipwreck reburial projects. In: Proceedings of the 9th ICOM Group on Wet Organic Archaeological Materials conference, Copenhagen, 7-11 June 2004

Wunderlich J, Müller S (2003) Non-linear echo sounders for high-res sub-bottom profiling. Seal Technol 44(9):23-26

Wunderlich J, Müller S, Erdmann S, Buch T, Hümbs P, Endler R (2005a) High-Resolution acoustical site exploration in very shallow water-a case study, Near Surface 2005. EAGE, Palermo

Wunderlich J, Wendt G, Müller S (2005b) High-resolution echo-sounding and detection of embedded archaeological objects with nonlinear sub-bottom profilers. Mar Geophys Res 26(2):123-133

Zisi A (2016) Relationship between wood density and ultrasound propogation velocity: a non-destructive evaluation of waterlogged archaeological wood state of preservation based on its underwater acoustic properties. PhD dissertation, University of Southampton

Open Access This chapter is licensed under the terms of the Creative Commons Attribution 4.0 International License (http://creativecommons. org/licenses/by/4.0/), which permits use, sharing, adaptation, distribution and reproduction in any medium or format, as long as you give appropriate credit to the original author(s) and the source, provide a link to the Creative Commons licence and indicate if changes were made.

The images or other third party material in this chapter are included in the chapter's Creative Commons licence, unless indicated otherwise in a credit line to the material. If material is not included in the chapter's Creative Commons licence and your intended use is not permitted by statutory regulation or exceeds the permitted use, you will need to obtain permission directly from the copyright holder. 